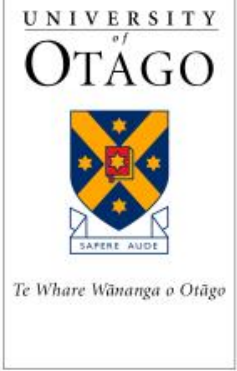

ISSN 0111-1760 (Print) ISSN 1178-2293 (Online)

University of Otago Economics Discussion Papers

No. 1012

School of Business

Unlimited Future, Unlimited Possibilities

September 2010

Te Kura Pakihi

\title{
Resource-based FDI and Expropriation in Developing Economies
}

Chris Hajzler

Address for correspondence:

Chris Hajzler

Department of Economics

University of Otago

PO Box 56

Dunedin

NEW ZEALAND

E-mail: chris.hajzler@otago.ac.nz

Telephone: 6434797387

Fax: 6434798174 


\begin{abstract}
Globally, foreign direct investment (FDI) assets are expropriated more in resource extraction industries compared to other sectors. Despite the higher apparent risk of expropriation in resources, countries more likely to expropriate also have a larger share of FDI in the resource sector. An incomplete markets model of FDI is developed to account for this puzzle. The type of government regime is stochastic, with low penalty regimes facing a relatively low, exogenous cost of expropriating FDI, and country risk is measured by the variation in these costs across different regimes. The key innovation of the model is that the government, before the regime type is known, is able to charge different prices to domestic and foreign investors for mineral rights. Granting cheap access increases FDI and reduces the country's share of resource rents, increasing the temptation to expropriate in a relatively low penalty regime. In very high-risk countries, subsidizing resource FDI increases the total value of output by raising investment, and the net gains from expropriating in a low penalty regime outweigh the rents foregone under a high penalty one. However, a stochastic resource output price results in relatively low-risk countries restricting FDI inflows to the resource sector instead - "windfall profits" in this sector raise incentives to expropriate when prices are high, yet minimization of the ex ante risk of expropriation is preferred owing to the relatively high penalty for expropriating. These results imply a higher average share of resource-based FDI in countries most likely to expropriate, while resources account for a high share of expropriated assets compared to the sector's global share of FDI. We show that the model is able to reconcile observed patterns of foreign investment and expropriation for a sample of 38 developing and emerging economies.
\end{abstract}

Keywords: Expropriation, Foreign Direct Investment, Natural Resources 


\section{Introduction}

Political risk is frequently cited as an important determinant of foreign direct investment (FDI) in developing countries. ${ }^{1}$ A relatively extreme but not uncommon form of political risk is expropriation, where a host-country government seizes company assets without fair compensation. This risk is particularly acute in resource-based sectors. Compared to the relative importance of these sectors in aggregate investment and output, foreign investment is expropriated more in mining and petroleum than in other industries. Hajzler (2012) examines the sectoral distributions of expropriation over the 1990-2006 period according to both number of firms and estimated value of assets seized, which are reproduced in Table 1. The proportion of assets expropriated in the primaries sector is high (almost 60\%) compared to the average developing country production shares (about 22\%), with the bulk of these acts occuring in mining and petroleum. Truitt (1970), Kobrin (1984), and Jones Jr (1993) examine evidence for this sectoral pattern over the 1960s and 1970s, employing various measures of expropriation. ${ }^{2}$ This observation has motivated several authors to examine industry-specific factors that increase the likelihood of expropriation in resources. The factors proposed include the prevalence of sunk costs in resources and mineral price volatility (Nellor, 1987; Monaldi, 2001; Engel and Fischer, 2010), varying uncertainty over project returns at different phases (Kobrin, 1980), and issues related to national economic security and strategic political objectives (Kobrin, 1980; Shafer, 2009).

Much less attention has been given to the apparent willingness of foreign investors to continue investing in resource extraction in several high-risk countries. In Bolivia, Ecuador, Russia, and Venezuela, for instance, large amounts of FDI are currently being expropriated in mining and petroleum, the same industries which had been nationalized in these countries several times during the past half-century. Repeating cycles of foreign investment and expropriation, particularly in extractive industries, have been well documented. ${ }^{3}$ There is also counter-intuitive evidence to suggest that developing countries that are more likely to expropriate do better in attracting resource-based FDI

\footnotetext{
${ }^{1}$ This includes risk associated with corruption, war, and expropriation. According to a recent survey conducted by the IMF Capital Markets Consultative Group (2003), most managers of companies engaged in FDI rank access to the legal system and the enforceability of contracts first in assessing the political risks associated with investing. (See Albuquerque, 2003; Alfaro, Kalemli-Ozcan, and Volosovych, 2008; Geiger, 1989; Jensen, 2006; Wei, 2000, for empirical evidence for the adverse impact of political risk on FDI.)

${ }^{2}$ Kobrin's (1984) expropriation data, which is also extended by Hajzler (2012) for the 1993-2006 period, is a frequency-based measure he refers to as an expropriation "act." Although a similar sector pattern of expropriation emerges using each of these measures of expropriation intensity, we focus on the distribution over the value of assets seized because this measure maps more naturally into our model's predictions.

${ }^{3}$ Hajzler (2012) notes that many of the countries expropriating during the 1990-2006 period have also nationalized the Mining and Petroleum sector at multiple points over the past century - Argentina (1963, 1974), Bolivia (1937, 1952, 1969, 2006), the Democratic Republic of Congo (1976, 1993), Ecuador (1969-1979, 2006), Indonesia $(1960,1965)$, Russia $(1918,2006)$ and Venezuela $(1975,2005)$ - as well as in the utilities sector - Indonesia $(1966,1976,1998)$ and Venezuela $(1963,1969)$. Other historical examples of "serial expropriators" are discussed in Gadano (2010) and Hogan, Sturzenegger, and Tai (2010). The latter note that host-countries, having felt the negative consequences of expropriation, will often offer very favorable deals to investors to entice them back: "Then the cycle may start again, with similar costs to both parties as before" (p.3).
} 
Table 1: Sector Expropriation Shares: Firms and Assets (1990-2006)

\begin{tabular}{|c|c|c|}
\hline 1990-2006 period & Firms $^{\mathrm{a}}$ & Value $^{\mathrm{b}}$ \\
\hline Primaries & 0.471 & 0.583 \\
\hline Agriculture & 0.074 & 0.004 \\
\hline Mining & 0.176 & 0.162 \\
\hline Petroleum & 0.221 & 0.416 \\
\hline Manufacturing & 0.176 & 0.094 \\
\hline Services & 0.353 & 0.323 \\
\hline \multicolumn{3}{|c|}{$\begin{array}{l}\text { a Excludes the } 50 \text { Dutch-owned farms } \\
\text { estimated to have been expropriated } \\
\text { in Zimbabwe in } 2005 . \\
\text { b Excludes Bolivia's Petrobas and Rus- } \\
\text { sia's Shakalin petroleum projects. } \\
{ }^{*} \text { Source: Hajzler (2012). }\end{array}$} \\
\hline
\end{tabular}

relative to the other sectors. In a cross-country comparison over the 1993-2006 period, Hajzler (2012) finds that the average share of resources in the total stock of FDI is higher among expropriating countries $(35 \%)$ in comparison to non-expropriating countries (16\%). This observation is surprising since resource-based FDI is subject to higher risk, and given that expropriating countries do not appear more highly resourcedependent. ${ }^{4}$ The relatively high resource-based FDI in countries that are likely to expropriate may help to explain why expropriations in resources are relatively common and are recurrent in many countries. Yet there is still a challenge in explaining what makes resource-based FDI relatively attractive in these countries. One possible interpretation is that governments offer incentives to foreign investors in the form of low royalty rates in risky investment climates. However, under what circumstances this arrangement would be desirable from the host country's perspective, and what the implications are for foreign investment patterns, remain unclear. ${ }^{5}$

This paper formally examines the impact of expropriation risk on sectoral patterns of FDI, focussing on the role of governments in managing the economy's stock of

\footnotetext{
${ }^{4}$ It would be less puzzling if these expropriating countries were also found to be particularly resourcedependent. In this case, one explanation would be that sectoral FDI patterns are driven primarily by a country's comparative advantage, and that countries with a comparative advantage in the relatively risky resource sectors, in turn, have a higher propensity to expropriate. However, a comparison of sector output shares does not reveal substantial differences between the two groups.

${ }^{5}$ Hajzler (2012) discusses evidence of this from published investor surveys, as well as other anecdotal evidence. Alternatively, it could also be argued that offering such incentives to foreign investors does not usually benefit the host country. Rather, the lack of transparency and accountability in many countries can allow corrupt governments to sell off mineral rights cheaply and to pocket much of the gains.
} 
mineral wealth. Host country governments typically decide how mineral rights are allocated and under what terms, and they can exercise a special influence over FDI in this sector that is not paralleled in other sectors. ${ }^{6}$ The question we ask is this: under what circumstances would governments want to partially offset the negative impact of political risk on FDI by offering mineral-rights more cheaply to foreign investors? The idea that governments are able to offset expropriation risk by providing "sweet deals" to foreign investors in the resource sector is not a new one (see, for example, Monaldi, 2001). In countries where a relatively low capital stock is a primary motivation for attracting FDI, cheap mineral rights may be an attractive substitute for direct subsidies. (Subsidies necessarily draw on already scarce domestic capital, which may be difficult financially and politically for many developing country governments.) We ask whether or not a host country benefits from offering more favorable terms to foreign investors in resources when country risk is high, and whether this can provide insight into the relatively large resource-based FDI in expropriating countries.

The two-sector environment that we consider builds on the single-sector, incomplete markets models of Eaton and Gersovitz (1984) and Cole and English (1991). These papers consider a capital poor country that benefits from capital inflows, or FDI, but where aggregate investment remains inefficiently low due to expropriation risk. There are no enforceable international regulations to protect investors, and a host country government that maximizes domestic welfare (or perhaps even its own coffers) is tempted to take these investments when their value is high. The payments the government collects from investors can not be conditioned on the the current and future profitability of the investment or on the costs of expropriating. ${ }^{7}$ As a result, selfenforcing contracts are impossible and foreign investors will always invest less than the efficient amount. The novel approach taken in this paper is to examine the role of the host country mineral contract in determining the patterns of foreign investment and expropriation at the sector level. The government's optimal allocation and pricing of mineral rights, as well as required investments in the resource sector, are evaluated at different levels of political risk. Of particular interest are the implications for FDI at the sector level.

We focus on two sources of uncertainty: stochastic resource output prices and a random external penalty to host country income if it expropriates. Changes in the expropriation penalty can represent variation in the external sanctions foreign investors (or their governments) can impose on the host-country, or may capture shifts in domestic political attitudes towards foreign investment. Political risk is then measured as the spread between the size of the expropriation penalty in the highest penalty regime

\footnotetext{
${ }^{6}$ Historically, utilities and banking have also been relatively vulnerable to expropriation. The utilities and banking sectors appear to share this feature of extractive industries insofar as governments can regulate market entry and offer companies monopoly profits, and the theoretical framework considered in this paper could potentially offer insight into expropriation in these sectors.

${ }^{7}$ This assumption also implies that expropriation can occur in equilibrium, which is consistent with observation. For an analysis of the effects of expropriation risk on patterns of FDI when contracts are complete, see Thomas and Worrall (1994). Here, the equilibrium contract delivers a positive share of the returns to the host-country only as necessary to deter expropriation - this allows the investor to recover its sunk investment costs sooner so that investment can be raised towards the efficient level, and expropriation never occurs.
} 
- representing a government with a high disincentive to expropriate - and the size of the penalty of the lowest penalty regime. A relatively low-risk country is one in which the expropriation penalty is similarly high for all regimes, whereas a relatively highrisk country is characterized by large swings in the incentive to expropriate across the different regimes.

We find that very high-risk countries benefit from offering mineral rights cheaply to foreign investors in order to raise FDI in resources, while relatively low-risk countries do better by restricting FDI to this sector. This reflects the host country government's desire to balance the goal of larger capital inflows, which it will occasionally be tempted to expropriate, with a credible commitment to not (or rarely) expropriate, which is costly. Only in a low penalty regime is the government tempted to expropriate, and this temptation increases with the mineral output price. When the lowest penalty is moderately large (i.e. the country is low risk), for given levels of aggregate FDI, the risk of expropriation is amplified as FDI is tilted towards resources. The reason is that, in addition to the ordinary returns to capital received by foreign investors in both sectors, investors in resources stand to earn positive ex post rents when faced with above average output prices. ${ }^{8}$ In order to reduce the temptation to expropriate in high price, low penalty states, mineral rights are allocated predominantly to domestic investors, shifting FDI to the non-resource sector. As country risk rises, however, the government is willing to expropriate at successively lower mineral output prices, and at some point ex post rents are fully appropriated by the host country in the low penalty regime. Increasing FDI in resources raises the probability of expropriation by less than an equal increase in non-resource FDI, and the government prefers to allocate mineral rights to foreign investors. Finally, in a very high-risk country, minimizing expropriation risk requires FDI to be far below the efficient level and the gains from increasing investment are large relative to the direct cost of expropriating. It is therefore optimal to increase investment in the resource sector (increasing the likelihood of expropriating in a low penalty regime) by lowering the price of mineral rights sufficiently to compensate foreign investors for the additional risk. Taken together, these results imply a positive average relationship between expropriation risk and the share of FDI in resources.

We calibrate the model and simulate sector FDI shares and expropriation probabilities for a sample of 38 developing and emerging economies. Predicted investment patterns and expropriation risk are broadly consistent with the data. Countries predicted to fall in the lowest risk category have expropriated much less, on average, compared to countries classified as moderate or high risk, and they are also predicted to have much lower shares of FDI located in the resource sector compared to relatively high risk countries. These results imply that the volume of foreign assets seized will be biased towards resources relative to the sector's average importance in GDP. Moreover, for each country in the sample, we compare both the predicted and the empirical FDI shares to the benchmark of a standard, competitive two sector model. Compared to this benchmark, our model predicts an adjustment in FDI shares in a direction of the

\footnotetext{
${ }^{8}$ In a low-risk country, expropriation occurs only in the highest price states since the cost of expropriating is high for even the low penalty regime. This implies a range of above average prices for which the investor walks away with positive ex post rents.
} 
empirical shares for more than $75 \%$ of the countries in the sample. Finally, the timing of expropriation in natural resource sectors often coincides with above average commodity prices both in the model and in the data. As we might expect, host-country governments are more likely to expropriate when the value of assets is high, whether they seek to maximize host-country welfare or to line their own pockets. (This is a key feature of the models of expropriation developed by Eaton and Gersovitz (1984), Cole and English (1991) - for certain host-country welfare functions - and Thomas and Worrall (1994).) The empirical tendency for governments to expropriate or raise tax and royalty rates when the mineral price is above trend is documented in Duncan (2005) and Hajzler (2012).

This paper complements a number of recent theoretical investigations of expropriation of foreign investment in natural resource sectors. Hogan et al. (2010), Engel and Fischer (2010), and Guriev, Kolotilin, and Sonin (2009) each examine resource sector contracts in the presence of expropriation risk. They note that, historically, investors' returns in this sector tend to be lower than what is stipulated in their contracts when prices are high (due to expropriation), yet they are offered very favorable concessions when prices are low (which are not likely to be honored in the long run). Engel and Fischer (2010) show that deviations from a fixed payment schedule such as this can be an optimal response to expropriation risk in industries with large sunk investments. In their model, however, the probability of expropriation is an exogenous, positive function of project return and all investment is sunk investment. These assumptions allow the authors to focus on the effects of risk on the optimal allocation of returns in the resource contract. The analysis of this paper instead focuses on the relationship between country risk and sectoral patterns of expropriation and FDI. In Guriev et al. (2009), simple resource sector contracts are considered and expropriation is also endogenous, but they focus exclusively on the effects of output prices and institutional quality (which they represent by a high, constant cost of expropriating) on foreign investment and expropriation within a single sector.

Chang, Hevia, and Loayza (2010) show how endogenous cycles of FDI and expropriation in natural resources can arise within a dynamic, incomplete contracts environment. Their focus is on the links between private ownership, inequality and the government's desire to redistribute wealth, and they examine a single sector in isolation. Their theoretical analysis relates to several of stylized facts we consider in this paper and complement our main findings.

The rest of the paper is organized as follows. Section 2 and presents the basic model environment and defines the equilibrium strategies of investors and the host country government. In section 3, a simplified version of the model with no resource output price uncertainty and a simple resource contract is used to emphasize main intuition for why very high-risk countries offer mineral rights cheaply to foreign investors to maximize FDI in this sector. Section 4 considers equilibrium with a stochastic resource output price, and demonstrates the additional implications of price volatility on the optimal choice of resource contract at different levels of country risk. The model's key results are generalized for a broader range of resource contracts, including ad valorem royalty-based payments, in Section 5. Finally, Section 6 presents the empirical results for the calibrated model, and Section 7 concludes. 


\section{The Model}

Having reviewed the empirical facts and related literature, we present a static, twosector model of foreign investment and expropriation that is broadly consistent with these facts.

\subsection{Basic Environment}

The basic environment consists of a large number of foreign investors that compete for a limited number of projects in each of two sectors of the host country. The hostcountry is capital poor and is unable to finance all of these projects itself. Domestic and foreign capital are perfect substitutes in production, and the relatively high returns to capital in the host country provide a motivation for foreign investors to invest. For simplicity, it is assumed that there is no foreign borrowing, so all capital inflows take the form of FDI. ${ }^{9}$

Production in each sector employs foreign and/or domestic capital and a sectorspecific domestic input. In the resource sector, this input is a mineral right. In the non-resource sector, domestic labor is employed. Output in each sector is produced using twice-differentiable, linear-homogenous production functions:

$$
\begin{aligned}
& X_{j}=F\left(K_{X j}, L_{j}\right) \\
& R_{j}=G\left(K_{R j}, M_{j}\right)
\end{aligned}
$$

where $R_{j}$ is the quantity of resource-sector output produced by firms of type $j$ and $X_{j}$ is the quantity of non-resource output by firms of type $j$ : either foreign $(j=f)$ or domestic $(j=h) . M_{j}$ is the quantity of the mineral rights leased by firms of type $j$. Similarly, $L_{j}$ denotes labor employed by each firm type, and $K_{i j}$ is investment in sector $i$. Aggregate stocks of labor $L$ and mineral rights $M$, as well as the total stock of domestic capital $K$, are fixed, and the stock of labor is normalized to 1 . We also assume $F(0, \cdot)=G(0, \cdot)=0$, and

$$
\lim _{K_{X} \rightarrow 0} F_{K}\left(K_{X}, \cdot\right)=\lim _{K_{R} \rightarrow 0} G_{K}\left(K_{R}, \cdot\right)=\infty
$$

where $F_{K}(\cdot)=\partial F / \partial K$ and $G_{K}(\cdot)=\partial G / \partial K$.

In the non-resource sector (henceforth "manufacturing"), both foreign and domestic firms compete for access to domestic labor and face a common labor price $w$. In

\footnotetext{
${ }^{9}$ Albuquerque (2003) considers both FDI and foreign borrowing in an imperfect contract enforcement environment, where the value of borrowed capital is fully appropriable whenever default occurs but only a fraction of the value of FDI can be appropriated. (This captures the notion that FDI is often accompanied by firm-specific managerial or organizational expertise that is costly or impossible for the host country to acquire.) In his analysis, FDI and borrowed or equity capital occur in distinct sectors and are therefore imperfect substitutes. In the context of industries where FDI and equity capital are substitutes, however, the idea that it is relatively costly for the host country to appropriate FDI implies that this form of foreign investment is superior in the presence of expropriation risk, providing a rationale for focusing on FDI and abstracting from other types of capital inflows. I am grateful to one of the referees for pointing out this connection.
} 
the resource sector, by contrast, the mineral rights are allocated by the government in the form of resource contracts. The choice of resource contract is the main policy tool available to the government, and the contract stipulates transfers to the government as well as the investment obligations of the firm. One way to interpret the standard resource contract is as follows. For each concession and corresponding investment amount, domestic and foreign investors compete by offering payments $\tau_{h}$ and $\tau_{f}$ resulting in a schedules $\left[K_{R j}, \tau_{j}\right]$ for $j=h, f$. The government chooses the preferred contracts among foreign and domestic bidders and allocates mineral rights accordingly. The mineral price is assumed to be independent of the state of nature, a characteristic of the most commonly observed types of mineral contracts in developing countries.

Under this resource contract the host-country government exercises a significant influence over investment levels in this sector that it does not have in the other sector. This assumption is motivated by the observation that, in practice, the government exercises significant control over the supply and price of an essential input in production in resource extraction as well as contract terms, but typically does not in other sectors. ${ }^{10}$ Specific terms of mining contracts will typically jointly determine the quantity and form of payment for the mineral concession and the quantity of investment per concession. In the extreme, the entire set of investment obligations of each contracting party will be explicitly negotiated. More often, however, only part of the investment will be specified, as in the case of minimum investment requirements or when the development of specific infrastructure such as roads or ports is included in the contract, leaving the remaining capital investments up to the investor. A range of other contractual elements also influence investment intensity, such as cost-recovery limits, the pooling of production and exploration expenses for tax purposes, and environmental regulations (for instance, clean-up and restoration of the site at the end of production).$^{11}$

Investment is risky - there is a positive probability that foreign capital and derived output are seized by the host country government. That is, once the successful bidders for the resource contract as well as investors in the non-resource sector have invested and output is produced, the government may decide it is worthwhile to expropriate foreign investor assets. However, the relative costs and benefits to the host country from expropriating are unknown to both investors and the government at the time that investments are made. Specifically, agents face an uncertain relative mineral output price $p \in \mathcal{P}$ as well as a random penalty $a \in \mathcal{A}$ incurred by the host country if the

\footnotetext{
${ }^{10}$ Important exceptions may arise in industries where the government can guarantee market power, such as telecommunications and public works. Here the essential input is market access itself, and it is reasonable to think that governments should exercise a commensurate degree of influence in these industries as well. Specified investment amounts are also common in the utilities sector and for build-to-operate contracts in other industries.

${ }^{11}$ Raising cost-recovery limits, which cap the amount of investment expenditures that can be deducted from taxable income, makes investment more attractive. This mechanism is especially effective when decided in conjunction with the size and configuration of the exploration territory that forms the basis for the tax and exemptions. If the areas are large and contain "frontier" regions that require considerable exploration expense, relaxing cost-recovery limits can raise the amount of exploration (and future development of wells or mines) that takes place when exploration costs can be deducted from the income generated on the more profitable tracts. A thorough comparison of different types of contracts in the petroleum production sector is provided by Johnston (2007).
} 
government decides to expropriate. We also assume that foreign firm payments which is paid after revenues are received and only in the event their assets are not expropriated. A particular state $\{a, p\}$ is denoted $s \in S=\mathcal{A} \times \mathcal{P}$. The timing of the model is summarized as follows:

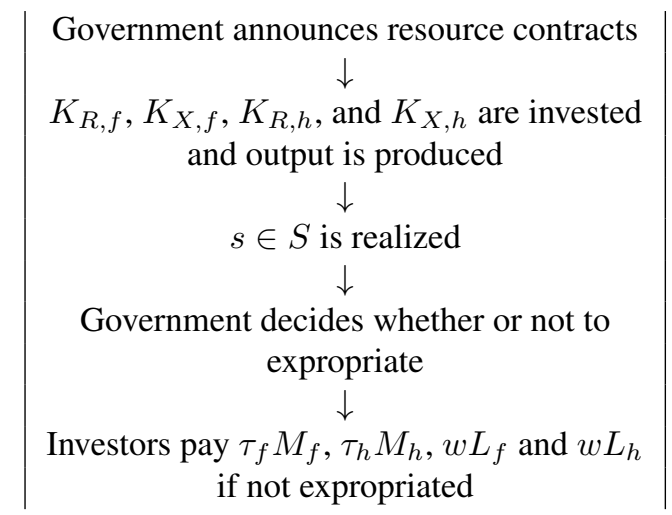

\subsection{Host Country Objective}

The host-country government is altruistic and chooses chooses a resource contracts that maximize what we refer to as host-country income. The objective function is a linear aggregator that takes into account the expected penalty incurred from expropriation.

If the government does not expropriate, the host country receives the value of domestic firm production plus the revenues from leasing the sector specific inputs to foreign firms, $\tau_{f} M_{f}$ and $w L_{f}$. If, on the other hand, the government expropriates, the host country claims the entire value of output of both sectors. The country also incurs penalty $a$ and forgoes domestic factor payments from investors whose assets have been seized. ${ }^{12}$

For ease of exposition, it is useful to define the vector of joint decisions taken prior to the expropriation decision as

$$
\theta=\left(M_{f}, M_{h}, K_{R f}, K_{R h}, K_{X f}, K_{X h}, \tau_{f}, \tau_{h}, L_{f}, L_{h}\right)
$$

and to define $D \subset S=\mathcal{A} \times \mathcal{P}$ as the set (possibly empty) of states in which the government expropriates, which depends on $\theta$. We refer to $D$ as the "default set".

Given any realization of a particular state, if the government does not expropriate, expected national income is

$$
Y^{N}(p, \theta)=F\left(K_{X h}, L_{h}\right)+p G\left(K_{R h}, M_{h}\right)+w(\theta) L_{f}+\tau_{f} M_{f}
$$

where $w(\theta)$ represents the equilibrium price of labor given $\theta$. If instead the government

\footnotetext{
${ }^{12}$ In the manufacturing sector, we assume that the government pays all workers from the revenues of its newly acquired state enterprise.
} 
chooses to expropriate, income is

$$
Y^{E}(p, \theta)-a=\sum_{j=h, f}\left(F\left(K_{X j}, L_{j}\right)+p G\left(K_{R j}, M_{j}\right)\right)-a
$$

Ex ante host-country income is

$$
V(\theta)=\int_{s \in D(\theta)}\left(Y^{E}(p, \theta)-a\right) h(s) d s+\int_{s \notin D(\theta)} Y^{N}(p, \theta) h(s) d s
$$

where $h(\cdot)$ is the joint probability density function over $\mathcal{A} \times \mathcal{P}$.

This treatment of the expropriation penalty as a deadweight loss is most closely related to the approach of Eaton and Gersovitz (1984) who consider a host country government that can expropriate foreign capital but is constrained from appropriating foreign managerial expertise, and where the domestic supply of managers is uncertain at the time of investment. (A country with a higher expected managerial capacity receives a comparatively low amount of FDI because the output loss associated with expropriation is relatively low.) In the dynamic models of expropriation considered by Cole and English (1991), Thomas and Worrall (1994) and Albuquerque (2003), the threat of being cut off from future foreign investment is a sufficient penalty to prevent the host country from finding it optimal to expropriate in all states, provided the government's discount factor is not too low. Unlike these models, future investment decisions are not relevant in the static environment that we consider here. However, the common features with these dynamic frameworks is a stochastic marginal utility of current consumption relative to the marginal utility of future consumption conditional on the decision to expropriate. ${ }^{13}$

Note that the penalty is independent of the value of output and investment seized. Hence there is no incentive for the government to partially expropriate foreign assets once this penalty is incurred.

\subsection{Investor Returns}

Foreign firms are assumed to fully commit to paying domestic factors conditional on their assets not being expropriated, and can delay payments until payments for production are received. Denoting by $\pi=\operatorname{Prob}(s \in D)$ the ex ante probability that expropriation occurs, expected returns to the representative foreign investor in the manufacturing sector is given by by

$$
E\left[\Pi_{X f}\right]=(1-\pi)\left(F\left(K_{X f}, L_{f}\right)-w L_{f}\right)-(1+r) K_{X f}
$$

\footnotetext{
${ }^{13}$ What is essential for FDI is that there is some positive, exogenous cost component associated with expropriation. Whether this is interpreted as a loss in output, as in the case of externally imposed sanctions, or as a lack of political support for such actions, does not matter. In the former case, the government objective function is expected national income, and in the latter case it is instead a government utility function that is linear over expected national income and the expected default penalty.
} 
where $r$ is the world risk-free rate of return on capital. (Without loss of generality, capital is assumed to fully depreciate.) Domestic investors do not face risk of expropriation, but must pay domestic capital $r^{h}$, and domestic investor returns are

$$
E\left[\Pi_{X h}\right]=F\left(K_{X h}, L_{h}\right)-w L_{h}-\left(1+r^{h}\right) K_{X h} .
$$

Resource sector contracts deliver the following returns to foreign and domestic investors:

$$
\begin{aligned}
& E\left[\Pi_{R f}\right]=(1-\pi)\left(E[p \mid s \notin D] G\left(K_{R f}, M_{f}\right)-\tau_{f} M_{f}\right)-(1+r) K_{R f} \\
& E\left[\Pi_{R h}\right]=E[p] G\left(K_{R f}, M_{f}\right)-\tau_{h} M_{h}-\left(1+r^{h}\right) K_{R h}
\end{aligned}
$$

where $E[p \mid s \notin D]$ is the expected price of the resource good given that expropriation has not occurred and $E[p]$ is the unconditional expected price.

\subsection{Equilibrium}

With the above definitions of production, resource contracts, investor returns, and host country income, we can define an open-economy equilibrium with foreign investment.

Definition 2.1. An open-economy equilibrium is a vector

$$
\theta=\left(M_{f}, M_{h}, K_{R f}, K_{R h}, K_{X f}, K_{X h}, \tau_{f}, \tau_{h}, L_{f}, L_{h}\right)
$$

as well as prices $w$ and $r^{h}$, default set $D$ and a probability of expropriation $\pi$ satisfying the following:

(i) Given $w, \pi$ and $r^{h}$, foreign and domestic manufacturing firms choose $\left\{K_{X f}, L_{f}\right\}$ and $\left\{K_{X h}, L_{h}\right\}$, respectively, to maximize (2) and (3).

(ii) The host country government chooses contracts $\left[K_{R f}, \tau_{f}\right]$ and $\left[K_{R h}, \tau_{h}\right]$ and allocates $M_{f}$ and $M_{h}$ to maximize (1) subject to the participation constraints of foreign and domestic firms, (4) > 0 and (5) > 0 , taking into account the optimal responses of firms in the manufacturing sector and corresponding changes in $D$.

(iii) Given $\theta, w, r^{h}$, and realization of $s \in \mathcal{A} \times \mathcal{P}$, expropriation occurs whenever the resulting net gain in host-country exceeds the penalty $a$ :

$$
s \in D \Leftrightarrow a<Y^{E}(p, \theta)-Y^{N}(p, \theta)
$$

(iv) Given $\theta$ and joint distribution $h(\cdot)$ over $\mathcal{A} \times \mathcal{P}$, the ex ante probability of expropriation is

$$
\pi=\int_{s \in D} h(s) d s .
$$


(v) The domestic resource constraints are satisfied:

$$
\begin{aligned}
& M_{f}+M_{h}=M \\
& L_{f}+L_{h}=1 \\
& K_{X h}+K_{R h}=K
\end{aligned}
$$

Section 3 characterizes the equilibrium in the special case of a constant resource output price. This provides the benchmark for considering the importance of stochastic resource output price in Section 4. Several general properties of the equilibrium are described before considering these separate cases.

Equilibrium conditions (iii) and (iv) define mappings from the vector $\theta$ to the default set and probability of expropriation, respectively, $D(\theta)$ and $\pi(\theta)$. Observing $\theta$ and taking $w(\theta)$ and $\pi(\theta)$ as given, if there is positive foreign investment in the manufacturing sector, competitive foreign investors pay a wage to labor $L_{f}$ that satisfies their zero profit condition. The assumed homogeneity of the productions implies

$$
w(\theta)=F\left(k_{X f}, 1\right)-\left(\frac{1+r}{1-\pi(\theta)}\right) k_{X f}
$$

where $k_{X f}=K_{X f} / L_{f}$. Conditional on positive foreign investment in this sector, the foreign investor capital-labor ratio in manufacturing determines the equilibrium price of labor $w(\theta)$. If domestic investors operate in this sector, they pay $w(\theta)$ per unit of labor and choose $k_{X h}=K_{X h} / L_{h}$ to satisfy

$$
w(\theta)=F\left(k_{X h}, 1\right)-F_{K}\left(k_{X h}, 1\right) k_{X f}
$$

where $F_{K}(\cdot)=\partial F / \partial K_{h}$.

If $\pi(\theta)$ is continuous (or constant) around equilibrium $\theta$, the the foreign investment in manufacturing solves $F_{K}\left(k_{X}(\theta), 1\right)=(1+r) /(1-\pi(\theta))$. However, if $\pi(\theta)$ is discontinuous in the region of optimal foreign investment, where an incremental increase in $K_{X f}$ implies a discrete change in the default set $D(\theta)$, it is possible for a single investor to go from strictly positive to strictly negative expected returns by increasing $K_{X f}$ beyond some threshold $\hat{K}_{X f}(\theta) \leq K_{X f}(\theta)$. In this situation no investor would choose higher investment than $\hat{K}_{X f}(\theta)$, even though they may be earning positive expected profits. This scenario is depicted in Figure 1. For clarity, the resource output price is assumed to be constant in this example. The figure plots the expected profit functions $E\left[\Pi_{X f}\right]$ for the representative foreign firm corresponding to two different expropriation probabilities, $\pi_{1}<\pi_{2}$. In the event that the representative firm was able to take probability $\pi_{1}$ as given (hence facing profit function $\Pi_{X}\left(K_{x}, \pi_{1}\right)$ ), the profit maximizing level of investment is $\bar{K} \cdot{ }^{14}$ Contrast this with the case where increasing $K_{X}$ past $\hat{K}$ results in a discrete change in the default set. In the figure, this threshold is marked by a change in $Y^{E}-Y^{N}-a$ from a negative to a positive value for some

\footnotetext{
${ }^{14}$ In equilibrium, labor is paid its marginal product, shifting this curve downward such that profits are zero at this level of investment.
} 


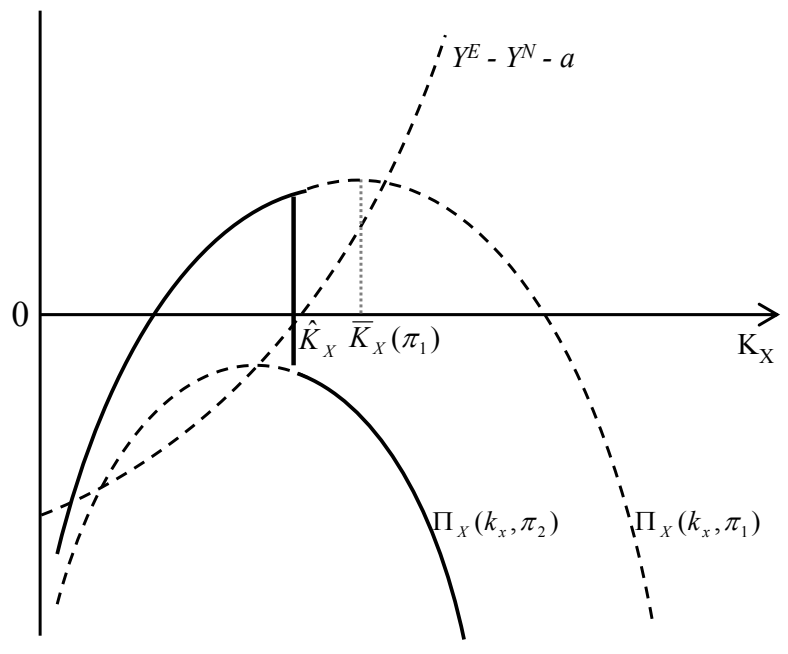

Figure 1: Investor Strategy in the Non-Resource Sector

penalty $a \in S$. In other words, for values of $K_{X}$ below $\hat{K}$, the net gain from expropriating when penalty $a$ is realized is negative and therefore $a$ is not included in the default set. For values of $K_{X}$ above $\hat{K}$, however, $a$ enters the default set and the probability of expropriation rises to $\pi_{2}$. Taking into account the expropriation decision of the government, then, the actual profit function of the firm is the solid curve, with the dashed portions corresponding to infeasible default sets. From this function it is clear that, if the jump in probability is large enough to result in negative expected profits for all foreign firms in the resource sector, no firm is willing to invest beyond $\hat{K}$.

More formally, consider any $K_{X f}^{1}$ (and corresponding default set $D\left(\theta_{1}\right)$ ) such that, for some $\left(a_{i}, p_{j}\right) \notin D^{1}$,

$$
a_{i}=Y^{E}\left(p_{j}, \theta_{1}\right)-Y^{N}\left(p_{j}, \theta_{1}\right) .
$$

Given $\theta$ and $p$, an increase in $K_{X f}$ holding other elements of $\theta$ constant increases $Y^{E}(p, \theta)-Y^{N}(p, \theta)$. Consider $\theta_{2}$, the initial vector of actions $\theta_{1}$ but with an arbitrarily small increase in $K_{X f}$. Then $\left\{a_{i}, p_{j}\right\} \in D\left(\theta_{2}\right)$. If $K_{X f}^{1}<\bar{K}_{X f}\left(\theta_{2}\right)$, then all firms are still earning positive expected returns after a very small increase in investment, and it is optimal to raise $K_{X f}$. Otherwise, increasing $K_{X f}$ results in negative expected returns and optimal investment is $K_{X f}^{1}$.

Equilibria with positive foreign and domestic investment in manufacturing are also characterized by $k_{X f}=k_{X h}=k_{X}(\theta) .{ }^{15}$ Therefore $k_{X}(\theta)$ is also aggregate capital

\footnotetext{
${ }^{15}$ Given that $F\left(k_{X f}, 1\right)-\left(\frac{1+r}{1-\pi(\theta)}\right) k_{X f}$ and $F\left(k_{X h}, 1\right)-F_{K}\left(k_{X h}, 1\right) k_{X h}$ are strictly concave, equal to zero at $k_{X j}=0$, and given $F\left(k_{X h}, 1\right)-F_{K}\left(k_{X h}, 1\right) k_{X h}$ is strictly increasing, equality between these functions to $w(\theta)$ implies that $k_{X f}=k_{X h}=k_{X}(\theta)$ in equilibrium at either 0 or $F_{K}\left(k_{X}, 1\right)=$
} 
invested in the manufacturing sector, and $k_{X}(\theta)=K-k_{R h}\left(M-M_{f}\right)\left(k_{R h}=\right.$ $K_{R h} /\left(M-M_{f}\right)$ ). Hence $k_{X}(\theta)$ pins down $L_{f}(\theta)$ and $L_{h}(\theta)$ given $k_{R h}$ and $M_{f}$ :

$$
L_{f}(\theta)=1-L_{h}(\theta)=\frac{k_{X}(\theta)-\left(K-k_{R h}\left(M-M_{f}\right)\right)}{k_{X}(\theta)} .
$$

Finally, $F_{K}\left(k_{X}(\theta), 1\right)=1+r^{h}(\theta)$, implying $1+r^{h}(\theta)=(1+r) /(1-\pi(\theta))$.

Successful bidders for the resource-sector contracts simply carry out the investment and payments specified in the contract chosen by the government (since all contracts deliver non-negative expected profits). This results in a schedule $\tau_{f}(\theta)$ for foreign investors (and an analogous schedule for domestic investors). This schedule leaves the foreign investor with zero expected profits:

$$
\tau_{f}(\theta)=E[p \mid s \notin D(\theta)] G\left(k_{R f}, 1\right)-\left(\frac{1+r}{1-\pi(\theta)}\right) k_{R f} .
$$

Given the payments made to labor and for access to mineral rights summarized by equations (6) and (7), it is straightforward to verify that expected host country income given by expression (1) is equal to:

$$
\begin{aligned}
V(\theta)= & F\left(K_{X h}, L_{h}\right)+F\left(K_{X f}, L_{f}\right)+E[p] G\left(K_{R h}, M_{h}\right)+E[p] G\left(K_{R f}, M_{f}\right) \\
& -(1+r)\left[K_{X f}+K_{R f}\right]-\pi(\theta) E[a \mid s \in D(\theta)] .
\end{aligned}
$$

where $E[p]$ is the unconditional average mineral output price. Moreover, substituting (6) and (7) into $Y^{E}(p, \theta)-Y^{N}(p, \theta), D(\theta)$ and $\pi(\theta)$ implicitly defined by

$$
s \in D(\theta) \Leftrightarrow a<(p-E[p \mid s \notin D(\theta)]) G\left(K_{R f}, M_{f}\right)+\frac{(1+r)\left(K_{X f}+K_{R f}\right)}{1-\pi(\theta)} .
$$

The equilibrium can be solved in two stages by backward induction where, in the second stage of the game, foreign and domestic firms adopt the optimal production and investment decisions just described conditional on the resource sector contracts, equilibrium prices, and the probability of expropriation. In the first stage of the game, the government chooses resource contracts that maximize (8), taking into account the optimal responses of firms and the corresponding effects on prices and the probability of expropriation. Given (7), this first stage collapses to a simultaneous decision over $\left(K_{R f}, K_{R h}, M_{f}\right)$.

\section{Equilibrium with a Constant Mineral Price}

In this section, we examine the relationship between country risk and sectoral patterns of FDI using a stylized example with a constant mineral output price and two potential

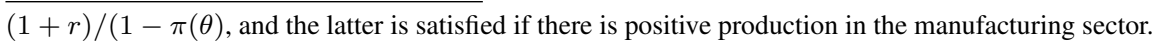


expropriation penalties faced by the host-country government:

$$
\mathcal{A}=\left\{a_{l}, a_{h}\right\} \sim\left\{\pi_{l}, 1-\pi_{l}\right\}
$$

Differences in country risk are considered by varying the distribution over these direct costs of expropriation. Specifically, political risk is measured as the difference in the size of expropriation penalty in the high penalty regime, $a_{h}$, representing a government with a high disincentive to expropriate, and the size of the low penalty, $a_{l} .{ }^{16}$ Without loss of generality, we fix $a_{h}$ at a value just above the level such that it could never be optimal for the government to expropriate such that $a_{l}$ as an inverse measure of country risk. In other words, $a$ is high for all political regimes in a relatively low risk country, whereas a relatively high risk country is characterized by large swings in the expropriation incentives of the different regimes. ${ }^{17}$

Depending on the equilibrium levels of foreign investment in both sectors, the probability of expropriation occurring is either zero or the probability of the low penalty regime, $\pi_{l}$. With a constant mineral price $p_{0}$, condition (9) implies that expropriation occurs with probability zero if and only if:

$$
a_{l} \geq(1+r)\left(K_{X f}+K_{R f}\right)=(1+r)\left(k_{X f} L_{f}+k_{R f} M_{f}\right)
$$

and expropriation occurs whenever $a_{l}$ is realized and $\pi(\theta)=\pi_{l}$. We refer to (NE) as the no-expropriation constraint. We assume that

$$
0 \leq a_{l}<\bar{a}=(1+r)\left(k_{X}^{F B}+k_{R}^{F B} M-K\right)
$$

where $k_{i}^{F B}$ is the efficient capital ratio in sector $i$. This ensures that expropriation risk matters for investment decisions (the interesting case) since it implies that efficient levels of investment in both sectors are not feasible.

We find that, for relatively high values of $a_{l}$ (a relatively low risk country), (NE) binds, expropriation never occurs and the optimal resource contract corresponds to a continuous range of foreign mineral rights allocations $M_{f}$. This implies that the resource sector FDI share is not uniquely determined. Moreover, the "average" share of FDI in the resource sector, defined as the median share across the set of all possible

\footnotetext{
${ }^{16}$ This notion of country risk is similar in spirit to that adopted by Cole, Dow, and English (1995) in their analysis of sovereign default, where a government transits through different political states that affect its valuation of future investments.

${ }^{17}$ An alternative approach would be to vary both $a_{h}$ and $a_{l}$ such that the expected value of $a$ is unchanged across different risk groups. This alternative approach would result in qualitatively identical results in terms of sectoral foreign investment patterns, which is the main focus of this analysis, and merely influences the threshold value of $a_{l}$ below which expropriation occurs with positive probability. The reason is that it is never optimal for foreign investor to invest beyond the point at which it is also optimal to expropriate in both states and, as we will demonstrate, optimal foreign investment only exceeds the threshold for which expropriation occurs in the low penalty state when the difference between $a_{l}$ and $a_{h}$ is large. Conversely, holding the difference between $a_{h}$ and $a_{l}$ constant but varying the expected value of the penalty is yet another way to conceive differences in country risk. It is not clear that the implications of the model are identical when country risk is modeled in this particular way. For the purposes of this analysis, however, our primary interest is the variation in the support of $a$, and for simplicity we focus on the size of $a_{l}$.
} 
equilibria, may be increasing or decreasing over a range of $a_{l}$ depending on a country's relative factor abundance and properties of the production functions. For relatively low values of $a_{l}$, by contrast, the government always expropriates in this state and the optimal resource contract results in no foreign investment in the manufacturing sector, while positive mineral rights are allocated to foreign investors to achieve the efficient investment level in the resource sector. This implies that resources FDI makes up 100\% of all FDI. The efficient investment level in resources is achieved despite a positive probability of expropriation by offering much lower mineral concession prices, which are paid in the event expropriation does not occur. These findings are summarized by the following propositions:

Proposition 3.1. For all $a_{l} \in[0, \bar{a}), k_{R h}=k_{R f}=k_{R}$ and $k_{X h}=k_{X f}=k_{X}$. Furthermore, provided $K$ is not too low, there exists $a^{\prime} \in(0, \bar{a})$ such that

1. for $a_{l} \in\left[0, a^{\prime}\right), k_{R}=k_{R}^{F B}, k_{X}=k_{X}^{F B}$, and $M_{f}=\min \{M, M-(K-$ $\left.\left.k_{X}^{F B} L\right) / k_{R}^{F B}\right\}$ and $L_{f}=0$; expropriation occurs if and only if $a=a_{l}$.

2. for $a_{l} \in\left[a^{\prime}, \bar{a}\right), k_{R}<k_{R}^{F B}, k_{X}<k_{X}^{F B}$ and the host-country government is indifferent towards the allocation of $M_{f}$ and corresponding equilibrium $L_{f}$ that are consistent with sector investment $k_{X} L$ and $k_{R} M$; expropriation never occurs.

Proof. See appendix.

The optimal resource contracts for a relatively high risk country allocates a relatively large share of the stock of mineral rights to foreign investors, which increases domestic capital available for investment in the other sector and raises the wage rate. This renders foreign investment in this sector unprofitable given the positive probability of expropriation. Efficient levels of investment are achieved in both sectors. For the relatively high risk group, ex post host-country income is unambiguously higher in the event that $a=a_{l}$ (and expropriation occurs) compared to the income it would receive if investment were chosen to satisfy (NE). However, this benefit is at the cost of lower payments for mineral rights and income in the event expropriation does not occur. When country risk is low, $a_{l}$ is sufficiently high that the expected direct cost of expropriating exceeds the cost of lower aggregate FDI compared to the case where (NE) does not bind. However, the allocation of mineral rights between domestic and foreign investors is not uniquely determined for this low risk group. Consequently, the model does not imply any specific relationship between exogenous country risk and the resource FDI share within this high risk group when the mineral output price is constant. However, even in this simple example, the resource "average" FDI share is unambiguously higher in the case of high risk ((NE) does not bind) compared to the case where (NE) binds. A full characterization of variation in the share of FDI in resources at different levels of risk is provided in the following Lemma.

Lemma 3.2. If $K>0$, the "average" share of FDI in the resource sector $\hat{\sigma}_{R}=$ $\operatorname{med}\left(k_{R f} M_{f} /\left(k_{X f} L_{f}+k_{R f} M_{f}\right)\right)$ across the set of all equilibria, is strictly higher for a relatively high-risk country $\left(a_{l} \in\left[0, a^{\prime}\right)\right)$ compared to low-risk country $\left(a_{l} \in\left[a^{\prime}, \bar{a}\right)\right)$. Moreover, if $K \geq \max \left\{k_{X}^{F B} L, k_{R}^{F B} M\right\}, \hat{\sigma}_{R}$ is non-increasing over both $\left[0, a^{\prime}\right)$ and 
$\left(a^{\prime}, \bar{a}\right)$. If $K<\max \left\{k_{X}^{F B} L, k_{R}^{F B} M\right\}$ and the elasticity of manufacturing sector investment to an increase in $a_{l}$ is at least as high as the resource sector investment elasticity, $\hat{\sigma}_{R}$ is non-increasing over $\left[0, a^{\prime}\right)$ and $\left(a^{\prime}, \bar{a}\right)$ provided $K / M$ is not too low.

Proof. See appendix.

Although the correlation between sector FDI shares and country risk implied by Lemma 3.2 is ambiguous within risk categories due to a multiplicity of equilibria, Proposition 3.1 and Lemma 3.2 have a clear implication for the probability of expropriation between risk categories. Specifically, in a sample of randomly chosen equilibria across the different risk categoryes, the average resource FDI share will be strictly higher in countries that have expropriated compared to countries that have not. Comparing a very high risk country such as Bolivia to a very low risk country such as Malaysia, our results imply that the resource contract in the high risk country will tend to offer mineral rights more cheaply to foreign investors and is expected to have a larger proportion of aggregate FDI located in the resource sector.

This contrasts the equilibrium pattern that are predicted under a resource pricing scheme where the government does not influence investment intensity and domestic factors are paid their marginal products. Denoting the profit-maximizing capital ratios in each sector by $k_{R}$ and $k_{X}$ (which would be identical in this case given $1+r^{h}=$ $(1+r) /(1-\pi(\theta))$, equation (8) can be expressed as:

$$
\begin{aligned}
V(\theta)= & F\left(k_{X}(\theta), 1\right)+E[p] G\left(k_{R}(\theta), 1\right) M-(1+r)\left[k_{X}(\theta)+k_{R}(\theta) M-K\right] \\
& -\pi(\theta) E[a \mid s \in D(\theta)] .
\end{aligned}
$$

Therefore $V(\theta)$ does not depend on the allocation of labor or mineral rights between domestic and foreign firms. In particular, when (NE) does not bind and $\pi=\pi_{l}$, the host-country is indifferent in allocating $M$, and a range of possible equilibria exist with the bounds of "average" resource FDI share in Lemma 3.2 determined in the same way for relatively high risk and low risk group.

\section{Equilibrium with Price Uncertainty}

So far we have not considered variation in resource output prices. In this section we introduce random resource output prices and re-examine the average relationship between FDI and risk. Price uncertainty has substantive implications for the optimal resource contract in moderate risk countries. Governments in countries in the moderate to low risk category aim to minimize the ex ante risk of expropriation by limiting FDI to the resource sector and maximizing non-resource FDI, while countries in the moderate to high risk group minimize the likelihood of expropriation by maximizing FDI in resources instead. Lemma 3.2 still serves to illustrate the key predictions for resource contracts in very high risk countries. In addition, introducing mineral output price variability allows us to consider the positive correlation between mineral prices and the likelihood of expropriation observed in the data.

For simplicity, the cumulative distribution function for mineral output prices is assumed to be continuous and twice differentiable over a bounded (non-negative) inter- 
val:

$$
p \sim Z[\underline{p}, \bar{p}]
$$

and $a$ and $p$ are assumed to be independent.

The key implication of random prices in terms of player strategies is that the government's expropriation decision can be summarized by a choice of cutoff values for resource price, one for each penalty $a$, above which it is optimal to expropriate. This implies that the expropriation set is described by

$$
D\left(p_{l}^{*}(\theta), p_{h}^{*}(\theta)\right)=\left\{\left(p_{l}^{*}(\theta), \bar{p}\right],\left(p_{h}^{*}(\theta), \bar{p}\right]\right\}
$$

where $p_{k}^{*}(\theta)$ is the cutoff resource price whenever expropriation penalty $a_{k}$ is realized. So, for instance, if the government strategy is to never expropriate when facing the high penalty, but to expropriate when the penalty is low and the price is above some $p_{l}^{*}$, $p_{h}^{*}(\theta)=\bar{p}$, the expropriation set is simply $D\left(p_{l}^{*}(\theta), p_{h}^{*}(\theta)\right)=\left\{\left(p_{l}^{*}(\theta), \bar{p}\right]\right\}$. If, in addition, $p_{l}^{*}(\theta)=\bar{p}$, this signifies that expropriation is never optimal and $D\left(p_{l}^{*}(\theta), p_{h}^{*}(\theta)\right)$ is empty. The threshold values $p_{k}^{*}(\theta)(k=l, h)$, are defined by the following system of equations: for each $k$,

$$
p_{k}^{*}(\theta)=\left\{\begin{array}{lll}
\bar{p} & \text { if } & a_{k} \geq Y^{E}(\bar{p}, \theta)-Y^{N}(\bar{p}, \theta) \\
\underline{p} & \text { if } & a_{k}<Y^{E}(\underline{p}, \theta)-Y^{N}(\underline{p}, \theta)
\end{array}\right.
$$

and for all other $\theta, p_{k}^{*}(\theta)$ is implicitly defined by

$$
a_{k}=Y^{E}\left(p_{k}^{*}, \theta\right)-Y^{N}\left(p_{k}^{*}, \theta\right)
$$

where the explicit expression for $Y^{E}(p, \theta)-Y^{N}(p, \theta)$ is equation (9). The host-country government's objective function is (8) as before, and the probability of expropriation can be expressed as

$$
\pi(\theta)=\pi\left(p_{l}^{*}(\theta), p_{h}^{*}(\theta)\right)=\pi_{l} \int_{p_{l}^{*}(\theta)}^{\bar{p}} z(p) d p+\left(1-\pi_{l}\right) \int_{p_{h}^{*}(\theta)}^{\bar{p}} z(p) d p
$$

where $z(p)=\partial Z(p) / \partial p$. In this environment with a continuum of random prices, very small changes in FDI have a negligible effect the expropriation probability defined by equations (9) and (11), conditional on positive foreign investment in the resource sector. When there is foreign investment in resources, the competitive foreign investment decision in manufacturing satisfies $F_{K}\left(k_{X}(\theta), 1\right)=(1+r) /(1-\pi(\theta))$.

Introducing price uncertainty does not have any impact on equilibrium for the very high risk group, as these countries still expropriate whenever the low penalty is realized (regardless of the price). However, for the more moderate risk group, price uncertainty has an important effect on equilibrium outcomes. The main difference is that, when there is positive FDI in the resource sector, the potential for foreign investors to earn positive (ex post) rents in this sector when their assets are not expropriated (above what is earned by manufacturing firms) makes expropriating particularly attractive in some states. Specifically, the direct gain from expropriating is increasing in the difference between the realized price of resource output and the effective marginal revenues re- 
ceived by foreign investors, $p-E\left[p \mid s \notin D\left(p_{l}^{*}(\theta), p_{h}^{*}(\theta)\right)\right]$. The effective marginal product determines the price paid for each resource concession, and hence also the share of resource rents going to the host-country. Because these payments are not contingent on the price of output, investors earn high profits ex post when the price is high and assets are not expropriated. This results in a greater temptation to expropriate in high-price states, and this temptation increases in the amount of resource-based FDI. ${ }^{18}$

For those countries that anticipate relatively high expropriation penalties, reducing the temptation to expropriate in a low penalty regime (which is costly) is the preferred strategy. For the lowest level of country risk, this is achieved by funneling all domestic capital into the resource sector. For higher risk countries (yet not so risky that the government subsidizes resource FDI), concentrating FDI in the resource-sector minimizes expropriation risk. The reason is that foreign firms in this sector, conditional on not being expropriated, earn low or negative returns in the low penalty regime compared to foreign firms in the non-resource sector. Increasing FDI in resources therefore raises the probability of expropriation by less than an equal increase in non-resource FDI.

To provide a sharper illustration of these relationships, consider the case where it is never optimal to expropriate when sanctions are high $\left(p_{h}^{*}(\theta)=\bar{p}\right) .{ }^{19}$ For this case, the characteristics of the equilibrium solutions across varying levels of country risk $a_{l}$ are summarized by the following proposition:

Proposition 4.1. For all $a_{l} \in[0, \bar{a}), k_{X h}=k_{X f}=k_{X}$ in equilibrium. Provided $K$ is not too low and under certain conditions on $F(\cdot), G(\cdot)$, and $Z(\cdot)$ guaranteeing a unique solution to 2.1 , the interval $[0, \bar{a})$ can be partitioned into continuous subintervals $\mathcal{A}^{L}, \mathcal{A}^{M}$ and $\mathcal{A}^{U}$ such that

1. for $a_{l} \in \mathcal{A}^{L}, k_{R h}=k_{R f}=k_{R}^{F B}, k_{X}=k_{X}^{F B}, M_{f}=\min \{M, M-(K-$ $\left.\left.k_{X}^{F B} L\right) / k_{R}^{F B}\right\}$ and $L_{f}=0$; expropriation occurs if and only if $a=a_{l}$.

2. for $a_{l} \in \mathcal{A}^{M}, k_{R h}<k_{R f}<k_{R}^{F B}, k_{X}<k_{X}^{F B}, M_{f}=\min \{M, M-(K-$ $\left.\left.k_{X} L\right) / k_{R f}\right\}$ and $L_{f} \geq 0$; expropriation occurs if $a=a_{l}$ and $p>p_{l}^{0}$ for some $p_{l}^{*}=p_{l}^{0} \in[\underline{p}, \bar{p})$.

3. for $a_{l} \in \mathcal{A}^{U}, k_{R f}<k_{R h}<k_{R}^{F B}, k_{X}<k_{X}^{F B}, M_{f}=\max \left\{0, M-K / k_{R h}\right\}$ and $L_{f}>0$. If $M_{f}>0$, expropriation occurs if $a=a_{l}$ and $p>p_{l}^{1}$ for some $p_{l}^{*}=p_{l}^{1} \in(\underline{p}, \bar{p}]$. Otherwise expropriation never occurs.

Moreover, if $\mathcal{A}^{M}$ is non-empty, $\mathcal{A}^{L}<\mathcal{A}^{M}<\mathcal{A}^{M}$ (that is $\sup \mathcal{A}^{L}=\inf \mathcal{A}^{M}$ and $\sup \mathcal{A}^{M}=\inf \mathcal{A}^{U}$ ) and $p_{l}^{0}<p_{l}^{1}$. If instead $\mathcal{A}^{M}$ is empty, $\mathcal{A}^{L}<\mathcal{A}^{U}$ and $\sup \mathcal{A}^{L}=$ $\inf \mathcal{A}^{U}$.

\footnotetext{
${ }^{18} \mathrm{~A}$ positive difference $p-E\left[p \mid s \notin D\left(p_{l}^{*}(\theta), p_{h}^{*}(\theta)\right)\right]$ is related to "windfall" profits in the sense that it captures the returns per unit of output in excess of what is received in the manufacturing sector (when expropriation does not occur). The average windfall profits could be reduced by setting a concession payment schedule that varies positively with the resource output price. This is commonly a feature of the optimal contract in a dynamic, complete markets framework.

${ }^{19}$ When only two possible penalties are assumed, this becomes the relevant case to consider. In our calibrated numerical exercise, $p_{h}^{*}(\theta)<\bar{p}$ occurs only when $a_{h}$ is sufficiently low and very close to $a_{l}$, and where there is a very large variance in the resource output price.
} 
Proof. See appendix.

Although a detailed proof is provided in the appendix, we provide some additional intuition here. For sufficiently low $a_{l}\left(a_{l} \in \mathcal{A}^{L}\right)$, the equilibrium is as described in Proposition 3.1.1 but where $p_{0}=E[p]$. In this case it is always optimal to expropriate when $a=a_{l}$, resource-based FDI is maximized and manufacturing FDI is zero. (See Section 3 for a complete description.)

At moderate risk levels, the government expropriates only when $a=a_{l}$ and the mineral output price exceeds a particular threshold price, conditional on positive $F D I$ in the resource sector. (With no resource-based FDI, manufacturing FDI is determined by the (NE) constraint and expropriation never occurs and, equivalently, $p_{l}^{*}=\bar{p}$.) To understand how the optimal resource contract varies across levels of $a_{l}$ for this more moderate risk group, it is useful to define $Q(x)=x-E[p \mid s \notin D(x, \bar{p})]$, where $Q(x)$ is strictly increasing in $x$ for $x \in[p, \bar{p}]$ given $Z$. Evidently $Q(\bar{p})>0$. Examining equation (9) which implicitly defines the price above which expropriation occurs in the low penalty regime, if $a_{l}$ is relatively high $\left(a_{l} \in \mathcal{A}^{U}\right)$ then for any amount of resource FDI, $k_{R f} M_{f}$, there is a unique $p_{l}^{*}>p$ satisfying this equality (taking into account the effects of $p_{l}^{*}$ on the probability of expropriation and manufacturing sector foreign investment) such that $Q\left(p_{l}^{*}\right) \geq 0$. In this case it is optimal to lower $M_{f}$ (to zero, if the domestic capital stock is sufficient to attain desired investment in this sector), because this permits a rise in $p_{l}^{*}$ for a given quantity of aggregate FDI, and therefore raises total FDI and $V(\theta)$. Expropriation risk is minimized, and the probability of expropriating is even zero if there is sufficient domestic capital to optimally allocate all mineral rights to domestic investors.

This policy is reversed whenever $Q\left(p_{l}^{*}\right)<0$, given the maximum attainable aggregate FDI. This condition holds for countries having a relatively low $a_{l}$, but not so low, however, that it is always optimal to expropriate whenever $a_{l}$ is realized $\left(a_{l} \in \mathcal{A}^{M}\right)$. In this case raising $M_{f}$ is optimal, since this permits a rise in aggregate FDI. The reason for this is that, when $Q\left(p_{l}^{*}\right)<0$, any "windfall profits" in the high-price, low penalty states are entirely appropriated by the host country in the low penalty regime when expropriation occurs. Conditional on not being expropriated in this state, the $e x$ post returns received by foreign firms in the resource sector are below that received by firms in the non-resource sector (and possibly even negative). Shifting FDI from the non-resource sector to the resource sector makes expropriation less attractive in the low penalty regime, for a given level of aggregate FDI. However, for some functional forms and parameter values it is possible that the threshold level of $a_{l}$ for which it is always optimal to expropriate in this state $\left(\sup A^{L}\right)$ is higher than the threshold level of $a_{l}$ such that $Q\left(p_{l}^{*}\right)<0$ at the corresponding levels of investment, in which case all countries would be classified in either the very high risk or very low risk groups $\left(\sup A^{L}=\inf A^{U}\right)$.

The implied expropriation pattern for countries in the moderate risk group $\left(a_{l} \in\right.$ $\mathcal{A}^{M}$ ) generates a positive relationship, on average, between resource output prices and the timing of expropriation. For this group, when a low penalty regime is realized, the host-country government expropriates if and only if the price exceeds the threshold price because this gives the host country higher ex post income/consumption given the size of the penalty compared to not expropriating. In this static environment, this result 
requires only that the objective function be strictly increasing in consumption/output. In a dynamic context where investors can threaten to cut off future investment if expropriation occurs, however, whether or not the host-country government in this group would be more tempted to expropriate when the resource output price is high or when it is low will also depend on the degree of risk aversion implied by the objective function, as shown in Cole and English (1991). In particular, in their dynamic one-sector model of expropriation where the relative value of domestic consumption and the continuation values of consumption under the contract is stochastic, sufficient concavity of the objective function in consumption/output implies that it is optimal to expropriate whenever the value of today's consumption is relatively low. This is because the increased marginal utility of not-expropriating when the value of output and production is low is high relative to the loss in future consumption from reduced foreign investment. Therefore in a dynamic environment, the prediction that expropriation tends to coincide with relatively high priced sates will depend on the government's degree of risk aversion as well as the type of research contract. ${ }^{20}$

\section{Ad Valorem and Other Royalty Payments}

In this section we consider a generalized version the resource contract of the previous section. This class of contracts includes a tax on the value of resource-sector output (rather than simply charging foreign investors a fixed price unit of mineral concessions). This type of payment arrangement is common under standard royalty contracts. We are interested such resource contracts because when resource output prices are variable it is conceivable that the fixed payment schedule assumed in the previous examples exaggerates the risk associated with resource FDI compared to a royalty contract. A pure ad valorem royalty payment is perfectly correlated with the resource output price. This implies that the temptation of governments in moderate risk countries to expropriate when the price is high is, at least partially, reduced. We establish a sufficient condition for the optimal contract to result in the same equilibrium relationships between country risk, allocation of mineral rights between foreign and domestic investors, and expropriation established by Proposition 4.1. Moreover, we show that this condition is satisfied by all resource contracts that include any combination of ad valorem royalty payments and fixed payments per unit of mineral concessions.

Denoting the total optimal resource sector tax payment for the representative foreign firm by $C\left(K_{R f}, M_{f}, p\right)$, the optimal contract renders the foreign investor indifferent between investing and not investing:

$$
\begin{aligned}
E\left[\Pi_{R f}\right]= & (1-\pi(\theta)) E[p \mid s \notin D(\theta)] G\left(K_{R f}, M_{f}\right)-(1+r) K_{R f} \\
& -(1-\pi(\theta)) E\left[C\left(K_{R f}, M_{f}, p\right) \mid s \notin D(\theta)\right]=0
\end{aligned}
$$

where $D(\theta)$ and $\pi(\theta)$ are determined by price cutoff rule $p_{l}^{*}$ following the logic of the

\footnotetext{
${ }^{20}$ Specifically, in addition to concavity of the objective function, whether or not expropriation is predicted to occur in high or low price states should also depend on how the host-country's share of current period returns relative to future expected returns varies in to the resource output price.
} 
previous section. This resource payment is more general because it may now depend on $p$. For example, an ad valorem royalty $\rho_{f}$ satisfying (12):

$$
E\left[\Pi_{R f}\right]=(1-\pi(\theta))\left(1-\rho_{f}\right) E[p \mid s \notin D(\theta)] G\left(K_{R f}, M_{f}\right)-(1+r) K_{R f}=0
$$

results in the following ex post royalty payment which increases proportionately with realizations of $p$ :

$$
\begin{aligned}
C\left(K_{R f}, M_{f}, p\right) & =\rho_{f}(\theta) \times p G\left(K_{R f}, M_{f}\right) \\
& =p\left(G\left(K_{R f}, M_{f}\right)-\left(\frac{1+r}{1-\pi(\theta)}\right) \frac{K_{R f}}{E[p \mid s \notin D(\theta)]}\right) .
\end{aligned}
$$

Note that the conditional expectation $E\left[C\left(K_{R f}, M_{f}, p\right) \mid s \notin D(\theta)\right]$ is equal to expected payment under the contract of the previous section, $\tau_{f}(\theta) M_{f}$, defined by (7). In fact, any resource contract satisfying (12) corresponds to identical ex ante expected share of resource sector returns for the host country and foreign investors:

$$
E\left[C\left(K_{R f}, M_{f}, p\right) \mid s \notin D(\theta)\right]=E[p \mid s \notin D(\theta)] G\left(K_{R f}, M_{f}\right)-\frac{(1+r) K_{R f}}{1-\pi(\theta)} .
$$

Therefore host-country income is given by (8) for any resource contract satisfying (12), and the host-country government problem differs across contracts only in terms of the ex post expropriation decision, which in turn defines the cutoff rule $p_{l}^{*}$. The general form of condition (10) defining cutoff $p_{l}^{*} \in(\underline{p}, \bar{p})$ is

$$
\frac{(1+r) K_{X f}}{1-\pi(\theta)}+p_{l}^{*} G\left(K_{R f}, M_{f}\right)-C\left(K_{R f}, M_{f}, p_{l}^{*}\right)-a_{l}=0 .
$$

It is possible to derive conditions on the resource contract that necessarily imply the same relationship between country risk, expropriation price thresholds, and mineral rights allocation that are already summarized by Proposition 4.1, assuming the contract satisfies the conditions for a unique solution to the government problem. A sufficient condition is established in the following lemma:

Lemma 5.1. Consider a continuous, differentiable payment schedule $C\left(K_{R f}, M_{f}, p\right)$ that satisfies (12), such that the representative foreign investor in the resource sector pays total amount $C\left(K_{R f}, M_{f}, p\right)$ in the event it is not expropriated. Any such payment schedule produces the equilibrium relationships between $a_{l}, M_{f}, k_{X}, k_{R f}, k_{R h}$ and threshold resource price $p_{l}^{*}$ summarized in Proposition 4.1 whenever it satisfies the following requirements:

$$
\begin{aligned}
& p_{l}^{*}>E[p \mid s \in D(\theta)] \quad \Leftrightarrow \quad p_{l}^{*} G_{K}\left(K_{R f}, M_{f}\right)-C_{K}\left(K_{R f}, M_{f}, p_{l}^{*}\right)>\frac{1+r}{1-\pi(\theta)} \\
& \text { and } \\
& p_{l}^{*}>E[p \mid s \notin D(\theta)] \quad \Rightarrow \quad p_{l}^{*} G_{M}\left(k_{R f}, 1\right)-C_{M}\left(K_{R f}, M_{f}, p_{l}^{*}\right) \geq 0 \\
& p_{l}^{*}<E[p \mid s \notin D(\theta)] \quad \Rightarrow \quad p_{l}^{*} G_{M}\left(k_{R f}, 1\right)-C_{M}\left(K_{R f}, M_{f}, p_{l}^{*}\right) \leq 0 .
\end{aligned}
$$


where

$$
C_{K}\left(K_{R f}, M_{f}, p_{l}^{*}\right)=\left.\frac{\partial C\left(K_{R f}, M_{f}, p\right)}{\partial K_{R f}}\right|_{p=p_{l}^{*}} .
$$

Moreover, a resource contract consisting of an ad valorem royalty, a fixed payment per unit of resource concessions, or a mixture of both that satisfies (12) will also satisfy these requirements.

Proof. See appendix.

Lemma 5.1 demonstrates that the equilibrium relationships outlined in the previous section correspond to a wide variety of resource sector contracts, including combinations of ad valorem royalties and fixed payments per concession typically observed in standard mining contracts. Specifically, under this broad class of conditional payments for mineral concessions, $p_{l}^{*}(\theta)$ is decreasing and $\pi(\theta)$ is increasing in country risk and, whenever $p_{l}^{*}>E[p \mid s \notin D(\theta)]$, the optimal policy is to lower $M_{f}$ towards zero (until all domestic capital is located in the resource sector). When the opposite inequality holds, but $p_{l}^{*}$ is above the threshold corresponding to the highest risk catogory, the optimal policy is to raise $M_{f}$ towards $M$ until all manufacturing sector investment is domestic capital. As a result, both the share of FDI in resources and the probability of expropriation are increasing in country risk for all such contracts, though investment and output levels may vary under the different types of contract. ${ }^{21}$

An example of a resource contract that does not result in these equilibrium relationships is one where the the entire ex post value of resource sector production accrues to the host country, but where foreign investors deduct the risk-adjusted value of their capital investments. Specifically, foreign investors pay, conditional on not being expropriated,

$$
C\left(K_{R f}, M_{f}, p\right)=p G\left(K_{R f}, M_{f}\right)-\left(\frac{1+r}{1-\pi(\theta)}\right) K_{R f}
$$

for all $p \in \mathcal{P}$. This payment schedule satisfies (12): ex post foreign investor profits in the resource sector equal $\pi(\theta)(1+r) K_{R f} /(1-\pi(\theta))$ when expropriation does not occur, and equal $-(1+r) K_{R f}$ when expropriation does occur.

Note that for any value of $p$,

$$
p G_{K}\left(K_{R f}, M_{f}\right)-C_{K}\left(K_{R f}, M_{f}\right)=\frac{1+r}{1-\pi(\theta)}
$$

and $p G_{M}\left(K_{R f}, M_{f}\right)-C_{M}\left(K_{R f}, M_{f}, p\right)=0$, and therefore only one of the two requirements for the condition outlined in Lemma 5.1 is satisfied. The reason is that, under such a contract, expropriation either always occurs in the low penalty regime or

\footnotetext{
${ }^{21}$ This suggests there are potential welfare implications from a choice over the type of resource payment at different levels of country risk a model of expropriation such as this one. See Engel and Fischer (2010) for a theoretical analysis along these lines.
} 
else never occurs:

$$
Y^{E}-Y^{N}-a_{l}=\left(\frac{1+r}{1-\pi(\theta)}\right)\left(K_{X f}+K_{R f}\right)-a_{l} .
$$

In other words, either $p_{l}^{*}=\underline{p}$ (and $\left.(1+r)\left[K_{X f}+K_{R f}\right]>\left(1-\pi_{l}\right) a_{l}\right)$ or $p_{l}^{*}=\bar{p}$ (and $\left.(1+r)\left[K_{X f}+K_{R f}\right] \leq a_{l}\right)$, as in the case with no resource-output price uncertainty.

\section{Numerical Results}

We illustrate the predicted relationships between country risk, sector production and FDI shares, and the probability of expropriation using a calibrated numerical example based on data for a sample of 38 developing and emerging economies over the period 1990-2006. ${ }^{22}$ For this exercise, we assume that aggregate output in each sector is produced using Cobb-Douglas production functions:

$$
\begin{aligned}
G\left(K_{R j}, M_{j}\right) & =K_{R j}^{\alpha} M_{j}^{1-\alpha} & & \alpha \in(0,1) \\
F\left(K_{X j}, L_{j}\right) & =K_{X j}^{\gamma}\left(A L_{j}\right)^{1-\gamma} & & \gamma \in(0,1)
\end{aligned}
$$

where $A$ is a labor-augmenting productivity parameter. For simplicity, it is also assumed that prices are uniformly distributed over the interval $[p, \bar{p}]$ :

$$
p \sim U[\underline{p}, \bar{p}] .
$$

This distribution implies the following simple expression for the probability of expropriation:

$$
\pi(\theta)=\frac{\bar{p}-\pi_{l} p_{l}^{*}(\theta)-\left(1-\pi_{l}\right) p_{h}^{*}(\theta)}{\bar{p}-\underline{p}} .
$$

Finally, we also maintain the simplifying assumption that $a_{h}$ is always sufficiently high that $p_{h}^{*}(\theta)=\bar{p}$. As discussed above, the qualitative results do not depend on changes in this assumption.

Technology parameters are chosen based on standard estimates in the literature, while country specific labor productivity, capital stocks and resource stocks are chosen to match simulated sector production with aggregate capital and FDI stocks and sector production shares in the data. Unless otherwise stated, all parameter estimates correspond to averages over 1990-2006 in the data. A government stability index is used to construct a measure of country risk, summarised by penalty parameter $a_{l}$. The simulated sector FDI shares for each country are then compared to empirical FDI shares estimates, and the predicted probabilities of expropriation among different country risk groups are compared to the corresponding country expropriation frequencies observed.

We assume $\gamma$ is equal to 0.33 based on the non-resource (manufacturing and services) capital income shares estimated by Valentinyi and Herrendorf (2008) for the

\footnotetext{
${ }^{22}$ The sample of countries is limited predominantly by the availability of data on sector FDI stocks.
} 
Table 2: Numerical Example: Parameter Values

\begin{tabular}{llll}
\hline Parameter & Value & Parameter & Value \\
\hline \hline$r$ & 0.05 & $\pi_{l}$ & 0.05 \\
$\alpha$ & 0.45 & $\gamma$ & 0.33 \\
$p$ & 0.05 & $\bar{p}$ & 1.5 \\
\hline
\end{tabular}

US economy. The authors do not estimate a separate capital income share for all primaries production, but their estimated share for Agricultural production is 0.54 , which excludes mining and energy sectors. We therefore assume a resource sector capital income share of 0.45 , approximately equal to the average of the corresponding shares of agriculture and manufacturing. ${ }^{23}$ The average resource output price, $E[p]$, is normalised to 1 and the support of resource output prices chosen to match the coefficient of variation on detrended petroleum and metals price indices from the IMF's International Financial Statistics. ${ }^{24}$ The annual risk-free interest rate $r$ is set to 0.05 , and $\pi_{l}$ is also set to 0.05 . The latter implies countries that are most likely to expropriate will expropriate with a $50 \%$ probability over a 17 -year period. ${ }^{25}$ The resultant set of parameter estimates are listed in Table 2.

In calibrating the remaining country-specific parameters, $A, K, M$ and $a_{l}$, we normalize $L=1$ and employ data on per capita sector production, capital stocks, and sector FDI stocks, as well as an index of government stability, for a sample of 38 developing and emerging economies. Total economy-wide capital is estimated from Penn World Tables (constant dollar) per capita gross capital formation data using the perpetual inventory method and assuming a geometric rate of depreciation equal to 0.06 . With this estimated total capital stock, $K P C A P=K+F D I$, we choose $A$ and $M$ to match predicted sector production with average annual sector value added data obtained from the United Nations' National Accounts Statistics: Main Aggregates and Detailed Tables. ${ }^{26}$ The sector-specific capital stocks (as well as the aggregate cap-

\footnotetext{
${ }^{23}$ We repeated the calibration exercise for different values between these two extremes and the main findings were not sensitive to this choice.

${ }^{24}$ The annual coefficient of variation over 1990-2006 for the metals price index after removing the linear trend is 0.31 and the corresponding value for petroleum is 0.36 . The standard deviation in prices corresponding to a uniform distribution is $\sigma_{p}=\sqrt{(\bar{p}-\underline{p})^{2} / 12}$, implying a coefficient of variation equal to $c v=\sigma_{p} / E[p]=(\bar{p}-p) / \sqrt{3}(\bar{p}+p)$. For $E[p]=1$, it is straightforward to verify that $b=\sqrt{3} c v+1$ and $a=2-b$. Assuming a value of $\bar{c} v=0.30$, the support of the resource output price is approximately $[0.5,1.5]$.

${ }^{25}$ Based on the full century of expropriation data of Tomz and Wright (2010), Kobrin (1984), Minor (1994) and Hajzler (2012), the average duration between expropriation acts among the ten countries that have expropriated FDI at least three times over the 1900-2006 is 15.5 years, with approximately half of the expropriation intervals between 5 and 15 years. (Expropriation acts within a five-year period are treated as a single event in these calculations.) Assuming this sample of serial expropriators represents countries most likely to expropriate, $\pi_{l}=0.05$ provides a good approximation of observed expropriation frequencies. However, the results are not highly sensitive to this choice.

${ }^{26}$ Specifically, we calibrate the model to match aggregate sector production shares when capital stocks are equal to investors' profit-maximising investment for a given domestic interest rate $r^{h}(\theta)$ and expropriation
} 
ital stock) used to evaluate the model's predicted foreign investment patterns are from Hajzler (2012).

The penalty parameter $a_{l}$ is a more challenging parameter to estimate given that there is no direct counterpart in the data. In the context of the model, the discrepancy between $a_{l}$ and $a_{h}$ (relative to optimal aggregate FDI) represents the magnitude in the shift in policy ideology between government regimes, at least with respect to foreign investment. The strategy we adopt is to estimate $a_{l}$ from an index of government stability $(G O V S T A B)$ for each country in the sample using the following formula:

$$
\frac{a_{l}}{F D I^{*}}=\nu_{1}+\nu_{2}(G O V S T A B)
$$

where $F D I^{*}$ represents the efficient level of aggregate foreign investment implied by the model given $K, G O V S T A B \in[0,1]$, and $\nu_{2}>0$. When $\nu_{1} \geq 0$ and $\nu_{2}=1$, for example, this mapping implies the country with the highest stability index is able to achieve the efficient level of investment without incurring any penalty in the model of Section $4\left(a_{l} \geq F D I^{*}\right)$, while countries with a lower index will face lower overall investment or a positive penalty. The stability index is taken from the Political Risk Services' International Country Risk Guide. This index is a score based on the level of a country's (i) government unity, (ii) legislative strength, and (ii) popular support. We normalize the index to take values between 0 and 1 based on the maximum and minimum values in our sample. The model is simulated for several different values of $\nu_{1}$ and $\nu_{2}$, and we present the results for the values that produce the closest fit with the data in terms of matching predicted expropriation frequencies within the three risk categories of Proposition $4.1\left(\nu_{1}=0.2\right.$ and $\left.\nu_{2}=0.6\right){ }^{27}$

The predicted and empirical sector foreign investment shares as well as the predicted probabilities of expropriation are compared for all countries in Table 3. Statistics are grouped according to country risk categories: $\pi(\theta)=0\left(a_{l} \in A^{U}\right), \pi(\theta) \in\left(0, \pi_{l}\right)$ $\left(a_{l} \in A^{M}\right)$ and $\pi(\theta)=\pi_{l}\left(a_{l} \in A^{L}\right)$. The first column reports the aggregate resourcesector investment shares predicted by a competitive, two-seater model calibrated to the empirical resource-sector value added for each country. ${ }^{28}$ If the government incentives

probability $\pi(\theta)$. This strategy involves guessing $r^{h}(\theta)$ (and hence $\pi(\theta)$ ), estimating domestic capital as the difference between the estimated capital stock per person and FDI per person, and setting $A$ and $M$ to match estimated value added per person in each sector. The model is then solved for sector capital stocks (which in our model need not equal the approximated levels implied by profit-maximising investment) and the domestic interest rate implied by the model. This process is repeated until convergence in the predicted interest rate is achieved. Using this procedure we are able to match the empirical sector production shares with a high degree accuracy ( \pm 1 percentage point for all countries in the sample).

${ }^{27}$ It may appear that this strategy for estimating $a_{l}$ is overly flexible in terms of the ability to match country risk levels and therefore resource FDI shares, the main variable of interest. However, provided $\nu_{2}>0$, the model predictions are significantly disciplined by the ordinal ranking of countries according to the stability index used, and the choice of $\nu_{1}$ and $\nu_{2}$ simultaneously influences the predicted expropriation thresholds for all countries in the sample.

${ }^{28}$ The equilibrium relationship between sector production and sector investment shares for Cobb-Douglas technology is

where $R=R_{h}+R_{f}$ and $X=X_{h}+X_{f}$

$$
\frac{K_{R}}{K_{X}+K_{R}}=\frac{\alpha E[p] R}{\alpha E[p]+\gamma X} .
$$


for allocating mineral rights between foreign and domestic investors predicted by our model are ignored, this share also corresponds to the expected resources FDI share, providing a benchmark against which to test the predictions of the model. The second column reports the empirical resources FDI share, and the third column contains the resource FDI shares predicted by our calibrated model. The fourth column contains the probability of expropriation implied by the model, and the final column contains an indicator variable that equals 1 if the country is recorded in the data to expropriate at least once over the 1990-2006 sample period.

Comparing the first and second columns, we observe lower resource FDI shares in the data compared to the investment shares implied by the standard competitive model on average for countries in the top portion of the table $(\pi(\theta)=0)$, and higher resource shares compared to those implied by the standard model on average for countries in the lower portions of the table $(\pi(\theta)>0)$. Specifically, the empirical resource FDI share for countries in the relatively low risk category is below the predicted equilibrium investment shares for 4 of the 25 countries in this group ( $84 \%$ of countries). The average discrepancy between predicted aggregate sector investment shares and estimated shares that is observed for relatively high risk countries is the opposite sign. Among countries with a positive predicted probability of expropriating in the model, the resource FDI share observed in the data exceeds the aggregate investment share for 9 of the 13 countries (70\% of countries). The bottom three rows of Table 3 report the average country shares for the three risk categories. The average empirical relationship between country risk and resources FDI is not monotonic across the three groups (the average predicted share for the highest risk group is slightly below that of the moderate risk group), which appears to be partially explained by the relatively high resource production shares among the intermediate country risk group in our sample. (These production shares, in turn, are largely pinned down by the stock of resource rights $M$, which we take to be exogenous.) Nevertheless, when comparing the relatively lowrisk country group and the highest risk group, predicted average resource FDI shares are relatively large for the latter group even though the average differences in aggregate sector capital and production shares between the two groups are comparatively small. This coincides with the empirical relationship between risk and sector FDI and production shares documented in Hajzler (2012). The author compares sector FDI and production shares across expropriating and non-expropriating countries over the same sample period and finds that the resource FDI share is significantly higher among expropriating countries compared to non-expropriating countries, even though sector value-added shares differ little between country groups. Specifically, the difference in average resource FDI shares between expropriating and non-expropriating countries is 24 percentage points, while the corresponding difference in resource output shares is -9 percent, as expropriating countries are slightly less resource-reliant. (See Table 4.)

The expropriation risk model with relative resource price uncertainty of Section 4 can help explain this average tendency as shown in the third column; for the relatively low risk (or politically stable) group, the host-country government has an incentive to minimize the allocation of mineral rights to foreign investors in order to maximize the quantity of aggregate FDI. Given the parameter estimates for our country sample, no mineral rights are allocated to foreign investors and the probability of expropriation is zero. Only when $a_{l}$ is sufficiently low is it optimal to allocate mineral rights to 
Table 3: Predicted Resource FDI Share and Exprop. Probability $\left(\nu_{1}=0.2, \nu_{2}=0.6\right)$

\begin{tabular}{lccccc}
\hline Country & $\begin{array}{c}\text { Res. Share } \\
(\text { Competitive })\end{array}$ & $\begin{array}{c}\text { Res. Share } \\
\text { (Data) }\end{array}$ & $\begin{array}{c}\text { Res. Share } \\
\text { (Model) }\end{array}$ & $\begin{array}{c}\pi(\theta) \\
\text { (Model) }\end{array}$ & $\begin{array}{c}\text { Exprop. }=1 \\
(1990-2006)\end{array}$ \\
\hline BGR & 0.227 & 0.015 & 0 & 0 & 0 \\
BRA & 0.112 & 0.016 & 0 & 0 & 0 \\
BWA & 0.477 & 0.561 & 0 & 0 & 0 \\
CHL & 0.159 & 0.375 & 0 & 0 & 0 \\
DOM & 0.135 & 0.009 & 0 & 0 & 1 \\
HND & 0.260 & 0.207 & 0 & 0 & 0 \\
HRV & 0.125 & 0.031 & 0 & 0 & 0 \\
IND & 0.352 & 0.078 & 0 & 0 & 0 \\
KOR & 0.073 & 0.009 & 0 & 0 & 0 \\
LTU & 0.124 & 0.013 & 0 & 0 & 0 \\
MOR & 0.232 & 0.174 & 0 & 0 & 0 \\
MEX & 0.081 & 0.020 & 0 & 0 & 0 \\
MOZ & 0.345 & 0.357 & 0 & 0 & 0 \\
MYS & 0.240 & 0.025 & 0 & 0 & 0 \\
PAK & 0.350 & 0.141 & 0 & 0 & 0 \\
PHL & 0.224 & 0.104 & 0 & 0 & 0 \\
RUS & 0.173 & 0.163 & 0 & 0 & 1 \\
SGP & 0.005 & 0.000 & 0 & 0 & 0 \\
SVK & 0.078 & 0.008 & 0 & 0 & 0 \\
THA & 0.164 & 0.042 & 0 & 0 & 0 \\
TUN & 0.216 & 0.478 & 0 & 0 & 0 \\
TUR & 0.199 & 0.025 & 0 & 0 & 0 \\
UGA & 0.461 & 0.044 & 0 & 0 & 0 \\
UKR & 0.277 & 0.050 & 0 & 0 & 0 \\
ZAF & 0.142 & 0.063 & 0 & 0 & 0 \\
\hline CRI & 0.142 & 0.224 & 0.998 & 0.033 & 0 \\
IDN & 0.306 & 0.560 & 0.894 & 0.034 & 1 \\
BOL & 0.272 & 0.422 & 0.997 & 0.034 & 1 \\
GUY & 0.631 & 0.692 & 0.902 & 0.035 & 0 \\
TTO & 0.217 & 0.264 & 0.673 & 0.039 & 0 \\
\hline ARG & 0.097 & 0.249 & 0.481 & 0.050 & 1 \\
COL & 0.230 & 0.197 & 1.000 & 0.050 & 0 \\
ECU & 0.320 & 0.671 & 1.000 & 0.050 & 1 \\
PER & 0.179 & 0.160 & 1.000 & 0.050 & 0 \\
PNG & 0.599 & 0.901 & 1.000 & 0.050 & 0 \\
POL & 0.091 & 0.006 & 0.727 & 0.050 & 0 \\
SLV & 0.154 & 0.009 & 1.000 & 0.050 & 0 \\
VEN & 0.249 & 0.405 & 1.000 & 0.050 & 1 \\
\hline Category Averages: & & & & & \\
$\pi(\theta)=0$ & 0.209 & 0.120 & 0 & 0 & 0.080 \\
$\pi(\theta) ~$ & 0.314 & 0.432 & 0.892 & 0.035 & 0.400 \\
$\left.\pi(\theta)=\pi_{l}\right)$ & 0.240 & 0.325 & 0.901 & 0.500 & 0.375 \\
\hline & & & & &
\end{tabular}


Table 4: Sector FDI and Output: Expropriators vs Non-Expropriators

\begin{tabular}{lcccc}
\hline & \multicolumn{2}{c}{ Non-Expropriators } & \multicolumn{2}{c}{ Expropriators } \\
& Average & $\mathrm{N}$ & Average & $\mathrm{N}$ \\
\hline \hline FDI (\% total) & & & & \\
$\quad$ Primaries & 15.9 & 39 & 34.5 & 9 \\
Manufacturing & 35.4 & 39 & 24.6 & 9 \\
$\quad$ Services & 48.7 & 39 & 40.9 & 9 \\
\hline Value Added (\% total) & & & & \\
$\quad$ Primaries & 21.8 & 39 & 16.5 & 9 \\
Manufacturing & 17.9 & 39 & 17.9 & 9 \\
$\quad$ Services & 60.3 & 39 & 65.7 & 9 \\
\hline
\end{tabular}

a Source: Hajzler (2012).

foreign investors, and it becomes worthwhile to expropriate when prices are high and the expropriation penalty is low. For the highest risk group, the share of mineral rights allocated to foreign investors is maximized in order to attain efficient investment levels given $\pi(\theta)=\pi_{l}$. This is achieved by setting a low rental price for mineral rights, indirectly subsidizing FDI in this sector. This provides a rationale for the positive monotonic predicted relationship between risk and the average resource FDI share, which is evident in the data.

Quantitatively, the resource FDI shares predicted by our model tend to substantially "overshoot" in terms of matching empirical foreign investment shares. This is evident from comparing average FDI shares across risk groups in the bottom three rows of Table 3. For countries in the relatively low risk category, the predicted $0 \%$ average resource FDI share is considerably lower than the empirical share, and the average predicted resource FDI share for the relatively high risk countries is much higher than the average shares in the data. However, several important determinants of FDI are not accounted for in our simple model that potentially work in the opposite directions. FDI is often accompanied by specialized technology and expertise that domestic investors may be unable to provide. In such cases it would be efficient for some foreign investors to invest in a given sector of the economy, independent of risk category, whenever the surplus benefit from foreign technology outweighs the cost of increased expropriation risk. This would result in minimum FDI shares in both resource and non-resource industries, shifting the average resource FDI shares in the direction of average aggregate investment shares. Moreover, a higher average risk of expropriation in resources, attributed to various potential factors in the expropriation literature (Kobrin, 1980; Shafer, 2009; Nellor, 1987; Monaldi, 2001; Engel and Fischer, 2010), would tend to lower resource sector FDI shares compared to those predicted by our model among relatively high-risk countries. With these additional factors in mind, we view our model as one that is able to explain the average deviations between the predicted foreign investment shares in the standard model from foreign investment patterns we observe, but which is nevertheless an incomplete account of foreign investment.

Comparing the average predicted expropriation probabilities and the frequency of expropriation across categories of country risk, we find that the qualitative predictions 
of the model are also broadly consistent with the data. Only $8 \%$ of countries in our predicted sample of relatively low risk countries have actually expropriated during the period under examination, while approximately $40 \%$ of countries in the medium and high risk countries are expropriators. (Dividing these averages by the 16 years of observations provides a rough estimate of the empirical probability of expropriation in a given year, though quantitatively we would expect these estimates to be imprecise due to the small sample size.) The government stability index, in the context of our model, provides additional insight into the determinants of expropriation risk across countries. Specifically, our model predicts a monotonic, decreasing relationship between government stability and the probability of expropriation.

A final empirical prediction of the model deserving mention is between the resource output price and the timing of expropriation. This positive relationship is driven by the expropriation strategies of governments in moderate risk countries. When expropriation does occur, the resource output price tends to be above average. For the highest risk group, there is no relationship between expropriation and the resource output price because expropriation always occurs in a low penalty regime.

\section{Conclusions}

By focusing on government choice of mineral contract in the context of a small, twosector open economy where FDI is risky and the future costs and benefits of expropriating are unknown, this paper provides a rationale for relatively high extractive industry FDI shares in countries most likely to expropriate. Specifically, the predictions of the incomplete markets model of FDI and expropriation considered in this paper reconcile a number of stylized facts. These are (i) a high global share of resource sector FDI in total expropriation compared to the sector's average production share; (ii) a positive relationship between mineral output prices and the timing of resource-sector expropriation; and (iii) an average share of primaries in total FDI that is higher in expropriating countries compared to non-expropriating countries, particularly in mining and petroleum, even though on average these country groups do not differ significantly in terms of sector production shares. The first two facts are well-documented in the literature, and have been used to support and/or motivate explanations for why FDI in extractive sectors is more vulnerable to expropriation. The third fact presents somewhat of a puzzle if expropriating countries are perceived by foreign investors as more likely to expropriate, and if resource-based FDI is particularly risky. We argue that the capacity (and incentive) for governments to offer mineral rights to foreign investors cheaply in countries characterized by a high degree political risk can help explain this puzzle.

Exogenous political risk is captured by the difference in the expropriation penalties between high-penalty and low-penalty regimes, where expropriation in the low penalty regime is very tempting for a relatively high risk country but still costly in a relatively low risk country. ${ }^{29}$ We find that countries in the highest risk category benefit from pro-

${ }^{29}$ As discussed in section 2.1, it is immaterial whether we view the temptation to expropriate as being re- 
moting FDI in the resource sector (and by lowering the cost of mineral rights) because, although this raises the likelihood that a future government will choose to expropriate and lowers FDI in the non-resource sector, the expected value of expropriated assets more than compensates for this loss. Governments in low and moderate risk countries instead aim to minimize the probability of expropriation for given levels of aggregate FDI. For the lower risk countries, this is accomplished by restricting resource-sector FDI because higher-than-average prices result in "windfall profits," and the temptation for a low penalty regime to expropriate in these states. In contrast, governments of moderate risk countries manage risk by concentrating FDI in resources - in the low penalty regime, when the government is most tempted to expropriate, resource sector firms earn below-average returns on their investments (conditional on not being expropriated), and the government is less likely to expropriate as FDI is concentrated in resources. These patterns are robust to alternative types of resource contract (such as a standard royalty payment) provided investment levels are also specified and contracts are incomplete.

These predictions for government policy towards resource-based FDI imply a positive average relationship between resource FDI shares and the probability of expropriation among countries of similar resource wealth and domestic capital stocks. ${ }^{30}$ This relative concentration of FDI in resources among countries most likely to expropriate implies that the total share of resource-based FDI in total assets expropriated globally will be higher than the average share of this sector in GDP. Quantitatively, the theory also helps to explain deviations in observed country sector FDI patterns from those predicted by a standard, competitive two-sector model.

Finally, the findings suggest that countries that have a poor record of expropriation, such as Bolivia, Ecuador, and Venezuela, may find that promoting relatively large amounts of FDI in resources is desirable and, for as long as default risk in these countries remains high, this suggests that a cycle of privatization and nationalization will persist. Moreover, because this implies that mineral rights should be offered to foreign investors on very favorable terms, this paper offers a novel perspective for the low government take in resources that has been documented in many countries. That foreign investors must be compensated for political risk if they are willing to invest is evident. However, this paper emphasizes that (i) subsidies to foreign investment will be most effective in resource sectors, where governments manage a key factor input and influence investment, and (ii) this policy is not likely to produce desirable results for countries at all levels of default risk. In particular, very high risk countries are expected to benefit from subsidizing resource FDI, while countries characterized by relatively low default risk do not. Governments of relatively low risk countries have a stronger incentive to minimize the ex ante risk of expropriating by restricting FDI in the resource sector if they anticipate the costs of expropriating will be high ex post.

lated to government regime characteristics or some other state of nature, such as the size of external sanctions imposed.

${ }^{30}$ This relationship is predicted "on average" because there are multiple equilibria for some risk levels. Moreover, because it is not monotonic, it depends to some extent on how countries are distributed according to political risk. 


\section{References}

Albuquerque, R., 2003. The composition of international capital flows: Risk sharing through foreign direct investment. Journal of International Economics 61, 353-383.

Alfaro, L., Kalemli-Ozcan, S., Volosovych, V., 2008. Why Doesn't Capital Flow from Rich to Poor Countries? An Empirical Investigation. The Review of Economics and Statistics 90 (2), 347-368.

Chang, R., Hevia, C., Loayza, N., 2010. Privatization and nationalization cycles. NBER working paper 16126.

Cole, H. L., Dow, J., English, W. B., 1995. Default, settlement, and signalling: Lending resumption in a reputational model of sovereign debt. International Economic Review 36 (2), 365-385.

Cole, H. L., English, W. B., 1991. Expropriation and direct investment. Journal of International Economics 30 (3-4), 201-227.

Duncan, R., 2005. Price or politics? an investigation of the causes of expropriation. Australian Journal of Agricultural and Resource Economics 50 (1), 85-101.

Eaton, J., Gersovitz, M., 1984. A theory of expropriation and deviations from perfect capital mobility. The Economic Journal 94, 16-40.

Engel, E., Fischer, R. D., 2010. The Natural Resources Trap: Private Investment without Public Commitment. MIT Press, Cambridge, MA, Ch. Optimal Resource Extraction Contracts under Threat of Expropriation, pp. 161-196.

Gadano, N., 2010. The Natural Resources Trap: Private Investment without Public Commitment. MIT Press, Cambridge, MA, Ch. Urgency and Betrayal: Three Attempts to Foster Private Investment in Argentina's Oil Industry, pp. 369-404.

Geiger, L. T., 1989. Expropriation and External Capital Flows. Economic Development and Cultural Change 37 (3), 535-556.

Guriev, S., Kolotilin, A., Sonin, K., June 2009. Determinants of Nationalization in the Oil Sector: A Theory and Evidence from Panel Data. Journal of Law, Economics, and Organization, 1-23.

Hajzler, C., 2012. Expropriation of Foreign Direct Investments: Sectoral Patterns from 1993 to 2006. Review of World Economics/Weltwirtschaftliches Archiv. 148 (1), $119-149$.

Hogan, W., Sturzenegger, F., Tai, L., 2010. The Natural Resources Trap: Private Investment without Public Commitment. MIT Press, Cambridge, MA, Ch. Contracts and Investment in Natural Resources, pp. 1-44.

IMF Capital Markets Consultative Group, 2003. Foreign Direct Investment in Emerging Market Countries. International Monetary Fund, Washington, D.C. 
Jensen, N., 2006. Nation-States and the Multinational Corporation: A Political Economy of Foreign Direct Investment. Princeton University Press, New Jersey.

Johnston, D., 2007. Escaping the resource curse. Columbia University Press, Ch. How to evaluate the fiscal terms of oil contracts, pp. 53-88.

Jones Jr, R. J., 1993. Multinational Corporations and Expropriation Risk. Multinational Business Review 1 (1), 44-55.

Kobrin, S. J., 1980. Foreign Enterprise and Forced Divestment in LDCs. International Organization 34 (1), 65-88.

Kobrin, S. J., 1984. Expropriation as an Attempt to Control Foreign Firms in LDCs: Trends from 1960 to 1979. International Studies Quarterly 28 (3), 329-348.

Minor, M. S., 1994. The Demise of Expropriation as an Instrument of LDC Policy, 1980-1992. Journal of International Business Studies 25 (1), 177-188.

Monaldi, F., 2001. Sunk-costs, Institutions, and Commitment: Foreign Investment in the Venezuelan Oil Industry. Unpublished manuscript, Stanford University, Department of Political Science.

Nellor, D. C., 1987. Sovereignty and Natural Resource Taxation in Developing Countries. Economic Development and Cultural Change 35 (2), 367-392.

Shafer, M., 2009. Capturing the Mineral Multinationals: Advantage or Disadvantage? International Organization 37 (01), 93-119.

Thomas, J., Worrall, T., 1994. Foreign direct Investment and the Risk of Expropriation. The Review of Economic Studies 61 (1), 81-108.

Tomz, M., Wright, M., 2010. The Natural Resources Trap: Private Investment without Public Commitment. MIT Press, Cambridge, MA, Ch. Sovereign Theft: Theory and Evidence about Sovereign Default and Expropriation, pp. 69-110.

Truitt, F. J., 1970. Expropriation of Foreign Investment: Summary of the Post World War II Experience of American and British Investors in the Less Developed Countries. Journal of International Business Studies 1 (2), 21-34.

Valentinyi, A. V., Herrendorf, B., 2008. Measuring factor income shares at the sectoral level. Review of Economic Dynamics 11, 820-835.

Wei, S. J., 2000. How taxing is corruption on international investors? Review of Economics and Statistics 82 (1), 1-11. 


\section{Appendices}

\section{A. Mathematical Appendix}

\section{A.A. Proof of Proposition 3.1}

The proof proceeds by describing the optimal investment and resource contract decisions when the no-expropriation binds $(\pi(\theta)=0)$ and when this constraint is violated $\left(\pi(\theta)=\pi_{l}\right)$. These cases are shown to correspond to two distinct regions of country risk, defined over values of $a_{l}$, and the implied relationship between country risk and the (expected) share of FDI located in the resource sector is considered in Lemma 3.2.

NE Binds and $\pi(\theta)=0$ : Consider first the case where NE binds, and assume $K_{X f}>$ 0 and $L_{f}>0$. From the no-expropriation constraint, $k_{X}(\theta)=\frac{K_{X f}}{L_{f}}=\frac{a_{l} /(1+r)-K_{R f}}{L_{f}}$.

Similarly, the resource constraint for domestic capital implies $k_{X}(\theta)=\frac{K_{X h}}{L_{h}}=\frac{K-K_{R h}}{L_{h}}$. Together, these conditions imply

$$
k_{X}(\theta)=\frac{\frac{a_{l}}{1+r}+K-K_{R f}-K_{R h}}{L}
$$

Substituting into expression (8) and setting $E[p]=p_{0}$, homogeneity of $F(\cdot)$ implies that we can express the host country decision over resource contracts as

$$
\begin{aligned}
\max _{\left\{K_{R f}, K_{R h}, M_{f}\right\}} V= & F\left(\frac{a_{l}}{1+r}+K-K_{R f}-K_{R h}, L\right)+p_{0} G\left(K_{R h}, M-M_{f}\right) \\
& +p_{0} G\left(K_{R f}, M_{f}\right)-a_{l}
\end{aligned}
$$

$V$ is strictly concave in each of the arguments, and the solution satisfies

$$
\begin{aligned}
& F_{K}\left(k_{X} \cdot 1\right)=p_{0} G_{K}\left(k_{R h}, 1\right) \\
& F_{K}\left(k_{X} \cdot 1\right)=p_{0} G_{K}\left(k_{R f}, 1\right) \\
& G_{M}\left(k_{R f} \cdot 1\right)=G_{M}\left(k_{R h}, 1\right) .
\end{aligned}
$$

The first two conditions imply $k_{R h}=k_{R f}=k_{R}$. The last condition is therefore redundant, and $M_{f}$ is not uniquely determined.

If instead $K_{X f}=L_{f}=0, k_{X}=k_{X h}$ does not depend on optimal foreign investment, and the decision over resource contracts is instead:

$$
\max _{\left\{K_{R h}, M_{f}\right\}} V=F\left(K-K_{R h}, L\right)+p_{0} G\left(K_{R h}, M-M_{f}\right)+p_{0} G\left(\frac{a_{l}}{1+r}, M_{f}\right)-a_{l}
$$

and the solution satisfies $F_{K}\left(k_{X}, 1\right)=p_{0} G_{K}\left(k_{R h}, 1\right)$ and $G_{M}\left(k_{R f}, 1\right)=G_{M}\left(k_{R h}, 1\right)$, again implying $k_{R h}=k_{R f}=k_{R}$. 
In both cases, host country income can be expressed as

$$
V_{N E}=F\left(k_{X}, 1\right) L+p_{0} G\left(k_{R}, 1\right) M-a_{l} .
$$

The marginal conditions indicate that aggregate investment and total sector specific factors of production, which are equal in both cases, are allocated in the same proportions, resulting in identical values of $k_{X}$ and $k_{R}$. Therefore the maximized values of $V$ are also equal and $K_{X f}=L_{f}=0$ is merely a special case of the general problem $K_{X f}, L_{f} \geq 0$. It follows that $M_{f}$ and $L_{f}$ are not uniquely determined, and equilibrium $k_{R}$ and $k_{X}$ satisfy

$$
k_{X} L+k_{R} M=\frac{a_{l}}{1+r}+K=\mathrm{FDI}+K
$$

and

$$
F_{K}\left(k_{X} \cdot 1\right)=p_{0} G_{K}\left(k_{R h}, 1\right) .
$$

NE Does Not Bind and $\pi(\theta)=\pi_{l}$ : Now consider the case where NE is violated, and assume $K_{X f}, L_{f}>0$. Foreign and domestic investors optimally choose $K_{X j}$ and $L_{j}$ to satisfy $F_{K}\left(k_{X j}, 1\right)=(1+r) /\left(1-\pi_{l}\right)$, and the corresponding capital to labor ratio in this sector $k_{X}^{c}<k_{X}^{F B}$ is determined by $r$ and $\pi_{l}$. The distribution of labor between domestic and foreign firms, in turn, depends on $k_{X}^{c}$ and the resource contracts:

$$
L_{h}=\frac{K_{X h}}{k_{X}^{c}}=\frac{K-K_{R h}}{k_{X}^{c}}, \quad L_{f}=L-\frac{K_{X h}}{k_{X}^{c}}=\frac{k_{X}^{c} L+K_{R h}-K}{k_{X}^{c}} .
$$

Using $k_{X h}=k_{X f}=k_{X}^{c}$ and the resource constraints, the host country decision over resource contracts can be expressed as

$$
\begin{aligned}
\max _{\left\{K_{R f}, K_{R h}, M_{f}\right\}} V= & \left(F\left(k_{X}^{c}, 1\right)-(1+r) k_{X}^{c}\right) L+p_{0} G\left(K_{R h}, M-M_{f}\right) \\
& +p_{0} G\left(K_{R f}, M_{f}\right)+(1+r)\left(K-K_{R h}-K_{R f}\right)-\pi_{l} a_{l}
\end{aligned}
$$

The optimal contracts satisfy $p_{0} G_{K}\left(k_{R h}, 1\right)=p_{0} G_{K}\left(k_{R f}, 1\right)=1+r$ which implies $k_{R h}=k_{R f}=k_{R}^{F B}$. The additional optimality condition $G_{M}\left(k_{R f} .1\right)=G_{M}\left(k_{R h}, 1\right)$ is therefore redundant, and $M_{f}$ is not uniquely determined.

If instead $K_{X f}=L_{f}=0, k_{X}=k_{X h}, k_{X}$ is determined by the resource contract, and the government problem is

$$
\begin{aligned}
\max _{\left\{K_{R f}, K_{R h}, M_{f}\right\}} V= & F\left(K-K_{R h}, L\right)+p_{0} G\left(K_{R h}, M-M_{f}\right)+p_{0} G\left(K_{R f}, M_{f}\right) \\
& -(1+r) K_{R f}-\pi_{l} a_{l} .
\end{aligned}
$$

The solution satisfies $F_{K}\left(k_{X} \cdot 1\right)=p_{0} G_{K}\left(k_{R h}, 1\right)$ and $G_{M}\left(k_{R f} .1\right)=G_{M}\left(k_{R h}, 1\right)$, again implying $k_{R h}=k_{R f}=k_{R}$. Finally, $p_{0} G_{K}\left(k_{R f} .1\right)=1+r$, implying $F_{K}\left(k_{X} .1\right)=$ $1+r$. Therefore $k_{X}=k_{X}^{F B}$ and $k_{R}=k_{R}^{F B}$, and optimal $M_{f}$ is unique: $M_{f}=$ $\min \left\{M, M-\left(K-k_{X}^{F B} L\right) / k_{R}^{F B}\right\}$. 
In both cases, expected host country income can be expressed as

$V_{\pi_{l}}=\left(F\left(k_{X}, 1\right)-(1+r) k_{X}\right) L+\left(p_{0} G\left(k_{R}, 1\right)-(1+r) k_{R}\right) M+(1+r) K-\pi_{l} a_{l}$.

Note $F\left(k_{X}, 1\right)-(1+r) k_{X}$ and $p_{0} G\left(k_{R}, 1\right)-(1+r) k_{R}$ are increasing for $k_{X} \leq k_{X}^{F B}$ and $k_{R} \leq k_{R}^{F B}$. Because $k_{X}^{c}<k_{X}^{F B}$, maximum expected host-country income corresponds to $K_{X f}=L_{f}=0$ as long as domestic capital $K$ exceeds $k_{X}^{c} L$. Below this threshold, restricting $L_{f}=0$ results in sub-optimally low investment in the manufacturing sector and the optimal contract instead results in positive foreign investment in this sector with $k_{X}(\theta)=k_{X}^{c}$.

Two Regions of Country Risk: $\left[0, a^{\prime}\right) \boldsymbol{\&}\left[a^{\prime}, \bar{a}\right)$ : Consider $a_{l}=\bar{a}-\epsilon_{a}$ for $\epsilon_{a} \approx 0$. Then there exist $\epsilon_{x}$ and $\epsilon_{r}$ satisfying $a_{l}=(1+r)\left(k_{X}^{F B} L-\epsilon_{x} L+k_{R}^{F B} M-\epsilon_{r} M-K\right)$ such that

$$
\begin{aligned}
V_{\epsilon}= & F\left(k_{X}^{F B}-\epsilon_{x}, 1\right) L+p_{0} G\left(k_{R}^{F B}-\epsilon_{r}, 1\right) M \\
& -(1+r)\left(\left(k_{X}^{F B}-\epsilon_{x}\right) L+\left(k_{R}^{F B}-\epsilon_{r}\right) M-K\right) \\
> & F\left(k_{X}^{F B}, 1\right) L+p_{0} G\left(k_{R}^{F B}, 1\right) M-(1+r)\left(k_{X}^{F B} L+k_{R}^{F B} M-K\right)-\pi_{l} a_{l} \\
= & V_{\pi_{l}}
\end{aligned}
$$

where $V_{\pi_{l}}$ is the income attainable when (NE) is violated. Therefore for sufficiently high $a_{l}$, the optimal resource constraint satisfies (NE).

Now consider some $a_{l}<\bar{a}$ and the corresponding optimal capital to labor ratios $\tilde{k}_{X}$ and $\tilde{k}_{R}$ satisfying (NE). Denote $\Delta k_{X}=k_{X}^{F B}-\tilde{k}_{X}, \Delta k_{R}=k_{R}^{F B}-\tilde{k}_{R}, \Delta X=$ $\left(F\left(k_{X}^{F B}, 1\right)-F\left(\tilde{k}_{X}, 1\right)\right) L$ and $\Delta R=p_{0}\left(G\left(k_{R}^{F B}, 1\right)-G\left(\tilde{k}_{R}, 1\right)\right) M$. Then

$$
\begin{aligned}
V_{\pi_{l}}-V_{N E} & =\Delta X+\Delta R+\left(1-\pi_{l}\right) a_{l}-\bar{a} \\
& =\Delta X+\Delta R-(1+r)\left(\Delta k_{X} L+\Delta k_{R} M\right)-\pi_{l} a_{l}
\end{aligned}
$$

Strict concavity of $F(\cdot)$ and $G(\cdot)$ implies that $\Delta X-\Delta k_{X} L$ and $\Delta R-\Delta k_{R} M$ are strictly positive and decreasing over $\tilde{k}_{X}$ and $\tilde{k}_{R}$ for $\tilde{k}_{X}<k_{X}^{F B}$ and $\tilde{k}_{R}<k_{R}^{F B}$. This implies that, for penalties $a_{l}$ below some threshold $a^{\prime}>0, V_{\pi_{l}}-V_{N E}>0$.

\section{A.B. Proof of Lemma 3.2}

When $a_{l} \in\left[a^{\prime}, \bar{a}\right)$, (NE) binds, $\pi(\theta)=0$ and $M_{f}$ is not uniquely determined. If $K$ is sufficiently large to cover optimal aggregate investment in either sector given $k_{X}$ and $k_{R}\left(K \geq K^{*}=\max \left\{k_{X} L, k_{R} M\right\}\right)$, the optimal range for $M_{f}$ is $[0, M]$. This implies that the share of FDI located in the resource sector, $\sigma_{R}=k_{R} M_{f} /\left(k_{R} M_{f}+k_{X} L_{f}\right)$, lies within the range [0.1]. We refer to the "average" resource FDI share as the midpoint of this range: $\hat{\sigma}_{R}=0.5$. When $a_{l} \in\left[0, a^{\prime}\right)$, (NE) does not bind and $\pi(\theta)=\pi_{l}$. In this case $L_{f}=0$ and therefore $\sigma_{R}=\hat{\sigma}_{R}=1$. Therefore $\hat{\sigma}_{R}$ is strictly greater for $a_{l} \in\left[0, a^{\prime}\right)$ compared to $a_{l} \in\left[a^{\prime}, \bar{a}\right)$, conditional on $K>K^{*}$.

However, if $a_{l} \in\left[a^{\prime}, \bar{a}\right)$ but $K<k_{R} M$, the lower bound on $M_{f}$ given $k_{R}$ and 
$k_{X}$ is $\underline{M}=M\left(1-\frac{K}{k_{R} M}\right)$ (since domestic capital stock is insufficient to cover all desired investment in resources) and the corresponding lower bound on $\sigma_{R}$ is $\underline{\sigma}_{R}=$ $\left(a_{l}-(1+r)\left[k_{X} L\right]\right) / a_{l}>0$. If $K<k_{X} L, k_{X} L_{f}=k_{X} L-K>0$ and the upper bound on $\sigma_{R}$ is $\bar{\sigma}_{R}=(1+r)\left[k_{R} M\right] / a_{l}<1$. It is possible to show that $\underline{\sigma}_{R}$ is strictly increasing and $\bar{\sigma}_{R}$ is strictly decreasing over $\left[a^{\prime}, \bar{a}\right)$ when these internal bounds are binding. This implies that the median share $\hat{\sigma}_{R}$ may be increasing or decreasing depending on which is binding, and this in turn depends on relative values of $M, L$, and $K$. If both are binding, whether $\hat{\sigma}_{R}$ is increasing or decreasing depends on the relative elasticities of $k_{R} M$ and $k_{X} L$, which in turn depends on relative capital intensities of production in each sector. In general, therefore, the relationship between $\hat{\sigma}_{R}$ and $a_{l}$ may be increasing, decreasing, or may even change sign over $\left[a^{\prime}, \bar{a}\right)$.

The derivatives of the lower and upper bounds with respect to $a_{l}$ can be expressed as

$$
\frac{\partial \underline{\sigma}_{R}}{\partial a_{l}}=\frac{(1+r) k_{X} L}{a_{l}^{2}}\left(1-\mu_{X}\right), \quad \frac{\partial \bar{\sigma}_{R}}{\partial a_{l}}=\frac{(1+r) k_{R} M}{a_{l}^{2}}\left(\mu_{R}-1\right)
$$

where $\mu_{X}=\left(\partial k_{X} L / \partial a_{l}\right)\left(a_{l} /\left(k_{X} L\right)\right)$ and $\mu_{R}=\left(\partial k_{R} M / \partial a_{l}\right)\left(a_{l} /\left(k_{R} M\right)\right)$ are the elasticities of total sectoral investment in response to an increase in $a_{l}$. This suggests the lower bound is increasing and the upper bound is decreasing if these elasticities are less than 1. Total differentiation of (NE) yields

$$
\mu_{X} k_{X} L+\mu_{R} k_{R} M=\frac{a_{l}}{1+r} .
$$

From the definition of (NE) it is straightforward to verify that $\mu_{X}+\mu_{R}<1$, and therefore $0<\mu_{X}, \mu_{R}<1$ is guaranteed if aggregate investment in both sectors increases with a relaxation in this constraint. Because this increasing lower bound will bind when $M$ is high relative to $K$ (otherwise the lower bound is constant at zero), whereas the decreasing upper bound binds when $L$ is high relative to $K$, this implies that $\hat{\sigma}_{R}$ is increasing in especially resource-abundant countries (high $M$ and low $L$ ) and decreasing in especially labor-abundant countries (low $M$ and high $L$ ). When both $M$ and $L$ are sufficiently high relative to $K$, both inner bounds will bind, and $\hat{\sigma}_{R}$ is increasing over $\left[a^{\prime}, \bar{a}\right)$ if and only if

$$
\frac{\partial\left(\underline{\sigma}_{R}+\bar{\sigma}_{R}\right)}{\partial a_{l}}>0 \Leftrightarrow \mu_{R}>1-\frac{1}{2}\left(\frac{K}{k_{R} M}\right) .
$$

Whether or not this condition is satisfied will depend on properties of $F(\cdot)$ and $G(\cdot)$, as well as $K / M$. However, because $k_{R} M>K, \hat{\sigma}_{R}$ is strictly decreasing for $\mu_{R}<0.5$, and a sufficient condition is $\mu_{R} \leq \mu_{X}$.

\section{A.C. Proof of Proposition 4.1}

The proof proceeds by describing the optimal investment and resource contract decisions when $\left(p_{l}^{*}-E[p \mid s \notin D(\theta)]\right) \geq 0$ and when $\left(p_{l}^{*}-E[p \mid s \notin D(\theta)]\right)<0$ where $p_{l}^{*}$ 
is implicitly defined by

$$
\begin{gathered}
(1-\pi(\theta))\left(p_{l}^{*}-E[p \mid s \notin D(\theta)]\right) G\left(K_{R f}, M_{f}\right)+(1+r)\left(K_{X f}+K_{R f}\right) \\
-(1-\pi(\theta)) a_{l}=0
\end{gathered}
$$

in conjunction with the definition of $\pi(\theta)=\pi\left(p_{l}^{*}, \bar{p}\right)$ in equation (11). We show that $(1-\pi(\theta))\left(p_{l}^{*}-E[p \mid s \notin D(\theta)]\right)$ is strictly increasing in $p_{l}^{*}$ and that (14) implies that $p_{l}^{*}$ is strictly decreasing in $a_{l}$ for $p_{l}^{*} \in(\underline{p}, \bar{p})$, and therefore $\left(p_{l}^{*}-E[p \mid s \notin D(\theta)]\right) \geq 0$ and $\left(p_{l}^{*}-E[p \mid s \notin D(\theta)]\right)<0$ correspond to two categories of country risk, $a_{l} \geq a^{\prime \prime}$ and $a_{l}<a^{\prime \prime}$. Properties of equilibrium in each case are then discussed, assuming conditions for uniqueness are satisfied. It follows from Proposition 3.1 that, for sufficiently low $a_{l}$, the equilibrium is as described in 3.1 .1 but where $p_{0}=E[p]$. The threshold level of country risk $a^{\prime}$ below which this describes the equilibrium, however, does not necessarily exceed $a^{\prime \prime}$. This implies that it is possible for there to be only be two relevant categories of country risk, $\left(p_{l}^{*}-E[p \mid s \notin D(\theta)]\right) \geq 0$ and $p_{l}^{*}=p$. However, provided that $a^{\prime \prime}>a^{\prime}$, then $\left(p_{l}^{*}-E[p \mid s \notin D(\theta)]\right)<0$ corresponds to a third, intermediate risk category. Whether there are two or three relevant categories of country risk, the share of resource FDI is increasing in country risk (and strictly increasing between between risk categories). Finally, sufficient conditions for uniqueness of equilibrium at each level of country risk are established.

At the Optimal Contract, $p_{l}^{*}$ is Strictly Decreasing in $a_{l}$ if $K_{R f}, M_{f}>0$ : Consider the case where $K_{R f}>0$ and $M_{f}>0$, implying that $k_{X}(\theta)$ is implicitly defined by $(1-\pi(\theta)) F_{K}\left(k_{X}, 1\right)=1+r$ and foreign and domestic firms employ identical capital to labor ratios. ${ }^{31}$ Aggregate manufacturing sector production is $F\left(K_{X f}+K-K_{R h}, L\right)$, manufacturing FDI is

$$
K_{X f}(\theta)=\Gamma(\theta)-\left(K-K_{R h}\right)
$$

where $\Gamma(\theta)=F_{K}^{-1}\left(\frac{1+r}{1-\pi(\theta)}\right)$. The government problem can be expressed as

$$
\begin{aligned}
\max _{\left\{K_{R f}, K_{R h}, M_{f}\right\}} V= & F(\Gamma(\theta), L)+E[p]\left(G\left(K_{R h}, M-M_{f}\right)+G\left(K_{R f}, M_{f}\right)\right) \\
& -(1+r)\left(K_{R f}+\Gamma(\theta)-\left(K-K_{R h}\right)\right)-\pi(\theta) a_{l} .
\end{aligned}
$$

subject to the usual non-negativity/resource constraints, (14) and (11). Assume for the moment an interior solution for both optimal $K_{R f}$ and $K_{R h}$. Taking into account the effects of the choice of resource contracts on $p_{l}^{*}, \pi(\theta)$ and $K_{X f}(\theta)$, the first-order

\footnotetext{
${ }^{31}$ When $K_{R f}=0$, either $\pi(\theta)=0$ or $\pi(\theta)=\pi_{l}$ and (NE) does not bind, and the equilibrium is as described in Proposition 3.1.
} 
conditions for the government problem are

$$
\begin{aligned}
& \frac{\partial V}{\partial K_{R f}}=E[p] G_{K}\left(k_{R f}, 1\right)-(1+r)-\Psi^{K_{R f}}=0 \\
& \frac{\partial V}{\partial K_{R h}}=E[p] G_{K}\left(k_{R h}, 1\right)-(1+r)-\Psi^{K_{R h}}=0 \\
& \frac{\partial V}{\partial M_{f}}=E[p]\left(G_{M}\left(k_{R f}, 1\right)-G_{M}\left(k_{R h}, 1\right)\right)-\Psi^{M_{f}}+\left(\lambda_{0}-\lambda_{1}\right)=0
\end{aligned}
$$

where

$$
\Psi^{X}=\left(\frac{\partial \pi(\theta)}{\partial p_{l}^{*}} \frac{\partial p_{l}^{*}}{\partial X}\right)\left(a_{l}-\left(F_{K}(\Gamma(\theta), L)-(1+r)\right) \Gamma_{\pi}\right)
$$

and where $\Gamma_{\pi}=\partial \Gamma(\theta) / \partial \pi<0 . \lambda_{0} \geq 0$ and $\lambda_{1} \geq 0$ are the multipliers on constraints $M_{f} \geq \underline{M}$ and $M_{f} \leq \bar{M}$ respectively, where $\underline{M}=\max \left\{0, M-K / k_{R h}\right\}$ and $\bar{M}=$ $\max \left\{0, M-\left(K-k_{X} L\right) / k_{R f}\right\}$. (These upper and lower bounds on $M_{f}$ are defined by Proposition 3.1. For simplicity, we ignore cary out the analysis taking these bounds as given, and ignore any effect of government decision over $K_{R f}$ and $K_{R h}$ on $V$ as a result of the potential effect on these bounds.) Complementary slackness implies $\lambda_{0}\left(M_{f}-\underline{M}\right)=0$ and $\lambda_{1}\left(\bar{M}-M_{f}\right)=0$. From (11), $\partial \pi(\theta) / \partial p_{l}^{*}=-\pi_{l} z\left(p_{l}^{*}\right)<0$ (given the assumption $p_{h}^{*}=\bar{p}$ ). Implicitly differentiating (14), we obtain the partial derivative of $p_{l}^{*}$ with respect to each choice variable:

$$
\begin{aligned}
\frac{\partial p_{l}^{*}}{\partial K_{R f}} & =-\frac{(1-\pi(\theta))\left(p_{l}^{*}-E[p \mid s \notin D]\right) G_{K}\left(k_{R f}, 1\right)+(1+r)}{\Omega}, \\
\frac{\partial p_{l}^{*}}{\partial K_{R h}} & =-\frac{(1+r)}{\Omega}, \quad \frac{\partial p_{l}^{*}}{\partial M_{f}}=-\frac{(1-\pi(\theta))\left(p_{l}^{*}-E[p \mid s \notin D]\right) G_{M}\left(k_{R f}, 1\right)}{\Omega}
\end{aligned}
$$

where

$$
\Omega=(1-\pi(\theta)) G\left(K_{R f}, M_{f}\right)-\pi_{l} z\left(p_{l}^{*}\right)\left(a_{l}+(1+r) \Gamma_{\pi}\right)
$$

is the slope of (14) with respect to $p_{l}^{*}$, given that

$$
\frac{\partial}{\partial p_{l}^{*}}(1-\pi(\theta))\left(p_{l}^{*}-E[p \mid s \notin D]\right)=1-\pi(\theta) .
$$

In the neighborhood of an equilibrium solution $\Omega>0$, implying that $p_{l}^{*}$ decreases, and hence $\pi(\theta)$ increases, as manufacturing sector FDI increases. This implies that $\partial p_{l}^{*} / \partial K_{R h}<0$, since $K_{X f}$ is increasing in $K_{R h}$ given aggregate investment. Intuitively, at the equilibrium level of manufacturing FDI, additional foreign investment in this sector must raise the benefit of expropriation relative to the cost. (This condition is automatically satisfied if, for instance, $F_{K}\left(K_{X}, L\right) K_{X}$ is strictly increasing.) Hence $\Psi^{K_{R h}}>0$. We can also verify that $\partial p_{l}^{*} / \partial K_{R f}<0$ in equilibrium. To see why, consider a capital to labor ratio $k_{R f}<k_{R}^{F B}$ in the neighborhood of the foreign firm's profit maximizing level, such that $1+r \approx(1-\pi(\theta)) E[p \mid s \notin D] G_{K}\left(k_{R f}, 1\right)$. Evidently, 
$\partial p_{l}^{*} / \partial K_{R f}$ is strictly negative, approximately equaling:

$$
-\frac{p_{l}^{*}(1-\pi(\theta)) G_{K}\left(k_{R f}, 1\right)}{\Omega}<0
$$

and only for $k_{R f}$ sufficiently below this ratio would there be a reversal in sign. However, given that $k_{X} \leq k_{X}^{F B}$,

$$
\Phi=-\left(\frac{\partial \pi(\theta)}{\partial p_{l}^{*}}\right)\left(a_{l}-\left(F_{K}(\Gamma(\theta), L)-(1+r)\right) \Gamma_{\pi}\right)>0 .
$$

Therefore $\partial p_{l}^{*} / \partial K_{R f}>0$ would imply that $\Psi^{K_{R f}}=-\left(\partial p_{l}^{*} / \partial K_{R f}\right) \Phi / \Omega<0$, and condition (15) in turn implies $k_{R f}>k_{R}^{F B}$, a contradiction. Hence $\partial p_{l}^{*} / \partial K_{R f}<0$ and $\Psi^{K_{R f}}>0$.

That (14) is strictly increasing in $p_{l}^{*}$ implies that $p_{l}^{*}$ is increasing and $\pi(\theta)$ is decreasing in $a_{l}$.

Three Categories of Country Risk: The first order conditions also imply that either $M_{f}=\underline{M}$ or $\bar{M}_{f}=M\left(\lambda_{0}>0\right.$ or $\left.\lambda_{1}>0\right)$. To see this, note that

$$
\frac{\partial p_{l}^{*}}{\partial M_{f}}=\frac{G_{M}\left(k_{R f}, 1\right)}{G_{K}\left(k_{R f}, 1\right)}\left[\frac{\partial p_{l}^{*}}{\partial K_{R f}}-\frac{\partial p_{l}^{*}}{\partial K_{R h}}\right] .
$$

Moreover, the conditions (15)-(16) imply

$$
\begin{aligned}
\frac{\partial p_{l}^{*}}{\partial K_{R f}}-\frac{\partial p_{l}^{*}}{\partial K_{R h}}= & \left(\frac{\partial \pi(\theta)}{\partial p_{l}^{*}}\left(a_{l}-\left(F_{K}(\Gamma(\theta), L)-(1+r)\right) \Gamma_{\pi}\right)\right)^{-1} \times \\
& \left(G_{K}\left(k_{R f}, 1\right)-G_{K}\left(k_{R h}, 1\right)\right) .
\end{aligned}
$$

Substituting these expressions for $\partial p_{l}^{*} / \partial M_{f}$ in (17) and simplifying yields

$$
\frac{G_{K}\left(k_{R h}, 1\right)}{G_{K}\left(k_{R f}, 1\right)}-\frac{G_{M}\left(k_{R h}, 1\right)}{G_{M}\left(k_{R f}, 1\right)}=\frac{\lambda_{1}-\lambda_{0}}{G_{M}\left(k_{R f}, 1\right)} .
$$

This equation implies that if $k_{R h} \geq k_{R f}$ then $\lambda_{1}-\lambda_{0}<0$ and hence $\lambda_{0}>0$ and $M_{f}=\underline{M}$. If $k_{R h}<k_{R f}$ then $M_{f}=\bar{M}$. Whether $k_{R h}>k_{R f}$ depends on $p_{l}^{*}$. Specifically, $\Psi^{K_{R f}}>0$ and $\Psi^{K_{R h}}>0$ are strictly decreasing in $\partial p_{l}^{*} / \partial K_{R f}$ and $\partial p_{l}^{*} / \partial K_{R h}$. Given $(1-\pi(\theta))\left(p_{l}^{*}-E[p \mid s \notin D]\right)$ is strictly increasing in $p_{l}^{*}$ and nonnegative if and only if $p_{l}^{*} \geq E[p \mid s \notin D]$,

$$
p_{l}^{*} \geq E[p \mid s \notin D] \quad \Leftrightarrow \quad \Psi^{K_{R f}} \geq \Psi^{K_{R h}} \quad \Leftrightarrow \quad k_{R f} \leq k_{R h} .
$$

This implies that $M_{f}=\underline{M}$ when $p_{l}^{*} \geq E[p \mid s \notin D]$ and $M_{f}=\bar{M}$ when $p_{l}^{*}<E[p \mid s \notin$ $D]$, conditional on optimal $p_{l}^{*}>\underline{p}$. Because $p_{l}^{*}$ is strictly decreasing in $a_{l}$ over the range $(p, \bar{p})$, these two scenarios correspond to two categories of country risk, where $a_{l}^{0} \in \mathcal{A}^{\bar{U}}$ and $a_{l}^{1} \in \mathcal{A}^{M}$ implies $a_{l}^{0}>a_{l}^{1}$.

Note that if either $\underline{M}=0$ or $\bar{M}=M$ then $K_{R f}=0$ or $K_{R h}=0$. For the 
former case, $p_{l}^{*}$ is no longer implicitly defined by (14), and instead the equilibrium is described by the previously considered case with no-price uncertainty when (NE) binds, but where $K_{R f}=M_{f}=0$. (In this case expropriation never occurs.) When $K_{R f}>0$, however, $p_{l}^{*}$ satisfies (14) and expropriation occurs whenever $a=a_{l}$ and $p>p_{l}^{*}$. Therefore when $a_{l} \in \mathcal{A}^{M}$ and $M_{f}=\bar{M}$, expropriation occurs with positive probability. For sufficiently low $a_{l}$, it is optimal to expropriate for any resource output price $p$ and equilibrium is described by 3.1.1, providing a third category of country risk such that $a_{l}^{0} \in \mathcal{A}^{L}$ and $a_{l}^{1} \in \mathcal{A}^{M}$ implies $a_{l}^{1}>a_{l}^{0}$. This will be true at a penalty level $a_{l}^{*}$ above that for which $p_{l}^{*}=p$ satisfies equation (14). Therefore it is possible that $\mathcal{A}^{M}$ is empty, where $\sup \mathcal{A}^{L^{-}}=\inf \mathcal{A}^{U}$. Otherwise, $\sup \mathcal{A}^{L}=\inf \mathcal{A}^{M}$ and $\sup \mathcal{A}^{M}=\inf \mathcal{A}^{U}$.

Sufficient Conditions for a Unique Solution to the Government Problem: We now describe sufficient conditions under which the first order conditions correspond to a unique solution. Specifically, sufficient conditions for strict concavity of $V$ are derived. These sufficient conditions for a unique solution are not necessary conditions, and a unique solution may still exist when they are violated. However, second order necessary conditions are not reducible to expressions that are easy to interpret, and we therefore consider sufficient conditions instead.

$V$ is strictly concave in $K_{R f}$ if (15) is strictly decreasing in $K_{R f}$. It is convenient to rewrite (15) as

$$
\chi G_{K}\left(k_{R f}, 1\right)-(1+r)\left(1+\frac{\Phi}{\Omega}\right)=0
$$

where

$$
\chi=\left(E[p]-\left(\frac{\Phi}{\Omega}\right)(1-\pi(\theta))\left(p_{l}^{*}-E[p \mid s \notin D]\right)\right) .
$$

The derivative of (15) with respect to $K_{R f} . \partial^{2} V / \partial K_{R f}^{2}$, is

$$
\begin{aligned}
& \chi G_{K K}\left(K_{R f}, M_{f}\right)-2\left(\frac{\partial p_{l}^{*}}{\partial K_{R f}} \cdot \frac{\Phi}{\Omega}\right)(1-\pi(\theta)) G_{K}\left(k_{R f}, 1\right)-\left(\frac{\partial p_{l}^{*}}{\partial K_{R f}}\right)^{2}\left(\frac{\Phi}{\Omega}\right) \times \\
& \times\left(\pi_{l} z\left(p_{l}^{*}\right) G\left(K_{R f}, M_{f}\right)-\pi_{l} z_{p}\left(p_{l}^{*}\right)\left(a_{l}+(1+r) \Gamma_{\pi}\right)+\left(\pi_{l} z\left(p_{l}^{*}\right)\right)^{2}(1+r) \Gamma_{\pi \pi}\right. \\
& \left.-\Omega \frac{z_{p}\left(p_{l}^{*}\right)}{z\left(p_{l}^{*}\right)}\right)+\left(\pi_{l} z\left(p_{l}^{*}\right)\right)^{2}\left(\frac{\partial p_{l}^{*}}{\partial K_{R f}}\right)^{2}\left(F_{K}(\Gamma(\theta), L)-(1+r)\right) \Gamma_{\pi \pi} \\
& +\left(\pi_{l} z\left(p_{l}^{*}\right)\right)^{2}\left(\frac{\partial p_{l}^{*}}{\partial K_{R f}}\right)^{2} F_{K K}(\Gamma(\theta))\left(\Gamma_{\pi}\right)^{2}
\end{aligned}
$$

where $G_{K K}\left(K_{R f}, M_{f}\right)=\partial^{2} G\left(K_{R f}, M_{f}\right) / \partial K_{R f}^{2}, \Gamma_{\pi \pi}=\partial^{2} \Gamma(\theta) / \partial \pi^{2}$ and $z_{p}\left(p_{l}^{*}\right)=$ $\partial z\left(p_{l}^{*}\right) / \partial p_{l}^{*}$. Given $\Gamma_{\pi}<0$ and $\Gamma_{\pi \pi}>0$, the above expression is negative if provided $\pi_{l} z\left(p_{l}^{*}\right)=-\partial \pi(\theta) / \partial p_{l}^{*}$ is not too large and $\Gamma(\theta)$ is not too small. To see why, first observe that provided $\pi_{l} z\left(p_{l}^{*}\right)$ is not too large, $\chi>0$. For $k_{R f} \leq k_{R f}^{F B}$, 
$E[p] \geq(1+r) / G_{K}\left(k_{R f}, 1\right), \chi$ is bounded below by

$$
\frac{1+r}{G_{K}\left(k_{R f}, 1\right)}-\left(\frac{\Phi}{\Omega}\right)(1-\pi(\theta))\left(p_{l}^{*}-E[p \mid s \notin D]\right) .
$$

Using the derived expression for $\partial p_{l}^{*} / \partial K_{R f}$, it is straightforward to verify that this expression is strictly positive if

$$
\frac{\partial p_{l}^{*}}{\partial K_{R f}}>-(1+r)\left(1+\frac{\Omega}{\Phi}\right)
$$

where

$$
\frac{\Omega}{\Phi}=\frac{(1-\pi(\theta)) G\left(K_{R f}, M_{f}\right)-\pi_{l} z\left(p_{l}^{*}\right)\left(a_{l}+(1+r) \Gamma_{\pi}\right)}{\pi_{l} z\left(p_{l}^{*}\right)\left(a_{l}-\left(F_{K}(\Gamma(\theta), L)-(1+r)\right) \Gamma_{\pi}\right)} .
$$

Because $a_{l}-\left(F_{K}(\Gamma(\theta), L)-(1+r)\right) \Gamma_{\pi} \geq 0$ and $(1-\pi(\theta)) G\left(K_{R f}, M_{f}\right)<0$, $\Omega / \Phi$ is strictly decreasing in $\pi_{l} z\left(p_{l}^{*}\right)$, and therefore for the lower $\pi_{l} z\left(p_{l}^{*}\right)$ the more likely (A.C) is satisfied. Evidently, as $\pi_{l} z\left(p_{l}^{*}\right)$ becomes small, $\Phi / \Omega$ is also reduced and $\chi G_{K K}\left(K_{R f}, M_{f}\right)<0$ in (18) must eventually dominate the sum of the remaining terms in this expression rendering the entire expression negative. However, even where $\pi_{l} z\left(p_{l}^{*}\right)$ exceeds this threshold level, a sufficient condition for (18) to be negative is

$$
\begin{gathered}
-\pi_{l} z\left(p_{l}^{*}\right) \frac{\partial p_{l}^{*}}{\partial K_{R f}}\left(\left(1-\frac{(1-\pi(\theta)) z_{p}\left(p_{l}^{*}\right)}{\pi_{l} z\left(p_{l}^{*}\right)^{2}}\right) G\left(K_{R f}, M_{f}\right)+\left(\pi_{l} z\left(p_{l}^{*}\right)\right)(1+r) \Gamma_{\pi \pi}\right) \\
-\left(\frac{\Omega}{\Phi}\right)\left(\pi_{l} z\left(p_{l}^{*}\right)\right)^{2}\left(\left(F_{k}(\Gamma(\theta))-(1+r)\right) \Gamma_{\pi \pi}+F_{K K}(\Gamma(\theta))\left(\Gamma_{\pi}\right)^{2}\right) \\
>2(1-\pi(\theta)) G_{K}\left(k_{R f}, 1\right)
\end{gathered}
$$

When $z_{p}\left(p_{l}^{*}\right) \approx 0$ and $\pi_{l} z_{(}\left(p_{l}^{*}\right) \Gamma_{\pi \pi} \approx 0$, this condition is satisfied if

$$
\frac{\partial p_{l}^{*}}{\partial K_{R f}}<-\frac{2(1-\pi(\theta)) G_{K}\left(k_{R f}, 1\right)}{\pi_{l} z\left(p_{l}^{*}\right) G\left(K_{R f}, M_{f}\right)} .
$$

The derivative of (16) with respect to $K_{R h}, \partial^{2} V / \partial K_{R h}^{2}$, is

$$
\begin{aligned}
& E[p] G_{K K}\left(K_{R h}, M_{f}\right)-\left(\frac{\partial p_{l}^{*}}{\partial K_{R h}}\right)^{2}\left(\frac{\Phi}{\Omega}\right) \times\left(\pi_{l} z\left(p_{l}^{*}\right) G\left(K_{R f}, M_{f}\right)\right. \\
& \left.-\pi_{l} z_{p}\left(p_{l}^{*}\right)\left(a_{l}+(1+r) \Gamma_{\pi}\right)+\left(\pi_{l} z\left(p_{l}^{*}\right)\right)^{2}(1+r) \Gamma_{\pi \pi}-\Omega \frac{z_{p}\left(p_{l}^{*}\right)}{z\left(p_{l}^{*}\right)}\right) \\
& +\left(\pi_{l} z\left(p_{l}^{*}\right)\right)^{2}\left(\frac{\partial p_{l}^{*}}{\partial K_{R h}}\right)^{2}\left(\left(F_{K}(\Gamma(\theta), L)-(1+r)\right) \Gamma_{\pi \pi}+F_{K K}(\Gamma(\theta))\left(\Gamma_{\pi}\right)^{2}\right) .
\end{aligned}
$$

Because the first term in this expression is negative for all parameter values, for sufficiently low value of $\pi_{l} z\left(p_{l}^{*}\right)$ this expression is negative. Moreover, even where 
$\pi_{l} z\left(p_{l}^{*}\right)$ exceeds this threshold level, it is straightforward to verify that $z_{p}\left(p_{l}^{*}\right) \approx 0$ and $\left.\pi_{l} z_{(} p_{l}^{*}\right) \Gamma_{\pi \pi} \approx 0$ are also sufficient to ensure this expression is negative.

Finally, the derivative of (17) with respect to $M_{f}$. $\partial^{2} V / \partial M_{f}^{2}$, is

$$
\begin{aligned}
& \chi G_{M M}\left(K_{R f}, M_{f}\right)+E[p] G_{M M}\left(K_{R h}, M-M_{f}\right) \\
& -2\left(\frac{\partial p_{l}^{*}}{\partial M_{f}} \cdot \frac{\Phi}{\Omega}\right)(1-\pi(\theta)) G_{M}\left(k_{R f}, 1\right)-\left(\frac{\partial p_{l}^{*}}{\partial M_{f}}\right)^{2}\left(\frac{\Phi}{\Omega}\right) \times \\
& \times\left(\pi_{l} z\left(p_{l}^{*}\right) G\left(K_{R f}, M_{f}\right)-\pi_{l} z_{p}\left(p_{l}^{*}\right)\left(a_{l}+(1+r) \Gamma_{\pi}\right)\right. \\
& \left.+\left(\pi_{l} z\left(p_{l}^{*}\right)\right)^{2}(1+r) \Gamma_{\pi \pi}-\Omega \frac{z_{p}\left(p_{l}^{*}\right)}{z\left(p_{l}^{*}\right)}\right) \\
& +\left(\pi_{l} z\left(p_{l}^{*}\right)\right)^{2}\left(\frac{\partial p_{l}^{*}}{\partial M_{f}}\right)^{2}\left(\left(F_{K}(\Gamma(\theta), L)-(1+r)\right) \Gamma_{\pi \pi}+F_{K K}(\Gamma(\theta))\left(\Gamma_{\pi}\right)^{2}\right) .
\end{aligned}
$$

Sufficient conditions for this expression to be negative are analogous to the conditions derived for $(18)<0$; note however that the conditions for $(21)<0$ are not as strict given that the second term, $E[p] G_{M M}\left(K_{R h}, M-M_{f}\right)$, is strictly negative for all parameter values.

\section{A.D. Proof of Lemma 5.1}

Equilibrium Properties of a General Class of Payment Schedules: Host-country income $V(\theta)$ is given by (8) for any resource contract corresponding to a payment schedule $C\left(K_{R f}, M_{f}, p\right)$ satisfying (12), as in the case of the specific resource contract considered in Section 4, and $p_{l}^{*}$ is implicitly defined by (10) (for $p_{l}^{*} \in(\underline{p} \cdot \bar{p})$ ) and $\pi(\theta)$ is defined by (11). This implies that the first-order necessary conditions corresponding to the government problem are identical to (15)-(17) of Proposition 4.1, given $\partial p_{l}^{*} / \partial X$, $X=\left\{K_{R f}, K_{R h}, M_{f}\right\}$. However, the general expression for (10) is given by (13), which produces the following expressions for $\partial p_{l}^{*} / \partial X$ :

$$
\begin{aligned}
\frac{\partial p_{l}^{*}}{\partial K_{R f}} & =-\frac{(1-\pi(\theta))\left(p_{l}^{*} G_{K}\left(k_{R f}, 1\right)-C_{K}\left(K_{R f}, M_{f}, p_{l}^{*}\right)\right)}{\Omega}, \\
\frac{\partial p_{l}^{*}}{\partial K_{R h}} & =-\frac{(1+r)}{\Omega}, \\
\frac{\partial p_{l}^{*}}{\partial M_{f}} & =-\frac{(1-\pi(\theta))\left(p_{l}^{*} G_{M}\left(k_{R f}, 1\right)-C_{M}\left(K_{R f}, M_{f}, p_{l}^{*}\right)\right)}{\Omega}
\end{aligned}
$$

where

$$
\begin{aligned}
\Omega= & \left(1-\pi(\theta)+\pi_{l} z\left(p_{l}^{*}\right)\right) G\left(K_{R f}, M_{f}\right)-\pi_{l} z\left(p_{l}^{*}\right)\left(a_{l}+(1+r) \Gamma_{\pi}\right) \\
& +\pi_{l} z\left(p_{l}^{*}\right) C\left(K_{R f}, M_{f}, p_{l}^{*}\right)-(1-\pi(\theta)) C_{p}\left(K_{R f}, M_{f}, p_{l}^{*}\right)
\end{aligned}
$$


and where $\partial p_{l}^{*} / \partial K_{R h}<0$ implies $\Omega>0$.

Suppose for the moment that the resource contract satisfies the requirement $p_{l}^{*}>$ $E[p \mid s \notin D(\theta)]$ if and only if

$$
(1-\pi(\theta))\left(p_{l}^{*} G_{K}\left(k_{R f}, 1\right)-C_{K}\left(K_{R f}, M_{f}, p_{l}^{*}\right)\right)>(1+r)
$$

in equilibrium. This would imply $p_{l}^{*}>E[p \mid s \notin D(\theta)]$ if and only if $-\partial p_{l}^{*} / \partial K_{R f}>$ $-\partial p_{l}^{*} / \partial K_{R h}$, and given equilibrium conditions (15)-(16):

$$
p_{l}^{*}>E[p \mid s \notin D(\theta)] \quad \Leftrightarrow \quad k_{R f}<k_{R h} .
$$

Inspection of condition (17) reveals that $k_{R f}<k_{R h}$ implies

$$
\left(\lambda_{0}-\lambda_{1}\right)-\Psi^{M_{f}}>0
$$

where $\lambda_{0}$ and $\lambda_{1}$ are the multipliers on the lower and upper bounds of $M_{f}$, and where

$$
\Psi^{M_{f}}=\left(\frac{\partial \pi(\theta)}{\partial p_{l}^{*}} \frac{\partial p_{l}^{*}}{\partial M_{f}}\right)\left(a_{l}-\left(F_{K}(\Gamma(\theta), L)-(1+r)\right) \Gamma_{\pi}\right)=-\frac{\Phi}{\Omega} \frac{\partial p_{l}^{*}}{\partial M_{f}},
$$

with $\Phi>0$. Therefore if, in addition to (22), $p_{l}^{*}>E[p \mid s \notin D(\theta)]$ should imply $\partial p_{l}^{*} / \partial M_{f} \leq 0$ and $p_{l}^{*}<E[p \mid s \notin D(\theta)]$ should imply $\partial p_{l}^{*} / \partial M_{f} \geq 0$ is also a requirement satisfied by payment schedule $C\left(K_{R f}, M_{f}, p\right)$, then $\lambda_{0}>0$ and $M_{f}=\underline{M}$ whenever $p_{l}^{*}>E[p \mid s \notin D(\theta)]$ and $\lambda_{1}>0$ and $M_{f}=\bar{M}$ whenever $p_{l}^{*}<E[p \mid s \notin$ $D(\theta)$ ]. This second requirement reduces to

$$
\begin{array}{lll}
p_{l}^{*}>E[p \mid s \notin D(\theta)] \quad & \Rightarrow \quad p_{l}^{*} G_{M}\left(k_{R f}, 1\right)-C_{M}\left(K_{R f}, M_{f}, p_{l}^{*}\right) \geq 0 \\
p_{l}^{*}<E[p \mid s \notin D(\theta)] \quad \Rightarrow \quad p_{l}^{*} G_{M}\left(k_{R f}, 1\right)-C_{M}\left(K_{R f}, M_{f}, p_{l}^{*}\right) \leq 0 .
\end{array}
$$

Taken together, these two requirements on the resource contract are sufficient to generate the equilibrium relationships summarized by Proposition 4.1.

Equilibrium Properties of Mixed Ad Valorem Royalty and Per Concession Payments: We demonstrate that a payment schedule based on either a percentage of the value of output or per unit of mineral concessions employed, or any mixture of each, satisfies the above sufficient condition, implying that these payment schedules produce the equilibrium relationships summarized in Proposition (3.1), when the equilibrium described is unique. Consider the payment schedule

$$
C\left(K_{R f}, M_{f}, p\right)=\rho_{f} p G\left(K_{R f}, M_{f}\right)+\tau_{f} M_{f}
$$

for any $\tau_{f} \geq 0$ and $\rho_{f} \in[0,1)$ that also satisfy the investors' zero profit condition, given $K_{R f}$ and $M_{f}$ :

$$
\left(1-\rho_{f}\right) E[p \mid s \notin D(\theta)] G\left(K_{R f}, M_{f}\right)-\tau_{f} M_{f}-\frac{1+r}{1-\pi(\theta)} K_{R f}=0 .
$$


Using this restriction to express $\tau_{f} M_{f}$ in terms of $\rho_{f}$ and substituting for $\tau_{f} M_{f}$ in $C\left(K_{R f}, M_{f}, p\right)$, we can express the payment schedule as

$$
\begin{aligned}
C\left(K_{R f}, M_{f}, p\right)= & E[p \mid s \notin D(\theta)] G\left(K_{R f}, M_{f}\right)-\frac{1+r}{1-\pi(\theta)} K_{R f} \\
& +\rho_{f}(p-E[p \mid s \notin D(\theta)]) G\left(K_{R f}, M_{f}\right) .
\end{aligned}
$$

Therefore

$$
\begin{aligned}
(1-\pi(\theta))\left(p_{l}^{*} G_{K}\left(k_{R f}, 1\right)\right. & \left.-C_{K}\left(K_{R f}, M_{f}, p_{l}^{*}\right)\right) \\
= & \left(1-\rho_{f}\right)(1-\pi(\theta))\left(p_{l}^{*}-E[p \mid s \notin D(\theta)]\right) G_{K}\left(k_{R f}, 1\right) \\
& +(1+r) .
\end{aligned}
$$

For $\rho_{f} \in[0,1)$, this expression is strictly greater than $(1+r)$ if and only if $p_{l}^{*}>$ $E[p \mid s \notin D(\theta)]$, satisfying the first requirement of the above condition. Moreover,

$$
p_{l}^{*} G_{K}\left(k_{R f}, 1\right)-C_{K}\left(K_{R f}, M_{f}, p_{l}^{*}\right)=\left(1-\rho_{f}\right)\left(p_{l}^{*}-E[p \mid s \notin D(\theta)]\right) G_{M}\left(k_{R f}, 1\right)
$$

which is strictly positive when $p_{l}^{*}>E[p \mid s \notin D(\theta)]$ and strictly negative when $p_{l}^{*}<$ $E[p \mid s \notin D(\theta)]$, satisfying the second requirement. 